\title{
COMISIÓN PARA EL MERCADO FINANCIERO: UN CAMBIO EN LA ARQUITECTURA DE SUPERVISIÓN FINANCIERA EN CHILE
}

\author{
Diego Morales López
}

Universidad Adolfo lbáñez

\begin{abstract}
RESUMEN: La Ley 21.000, promulgada en febrero de 2017, creó la Comisión para el Mercado Financiero y tuvo por objetivo modernizar el sistema chileno de supervisión financiera. En ese contexto, introdujo una promesa mayor: la integración en un único organismo de la Superintendencia de Valores y Seguros y la Superintendencia de Bancos e Instituciones Financieras. Esta concentración de ambas superintendencias en la Comisión traerá aparejado un cambio trascendental en la forma en que se concibe la regulación financiera en Chile. Este artículo pretende dar cuenta de las razones que justificaron la decisión de consolidar nuestro sistema de supervisión en un único organismo, así como de las implicancias relevantes que nacen del diseño institucional del nuevo regulador.

Palabras Clave: Comisión para el Mercado Financiero; supervisión financiera; regulación financiera; arquitectura de la supervisión financiera.
\end{abstract}

RECIBIDO: abril 2018; ACEPTADO: mayo 2018.

Diego Morales López. Abogado por la Universidad de Chile y profesor invitado en la Universidad Adolfo Ibáñez. Ex jefe de gabinete de la subsecretaría del Ministerio de Hacienda. Email: d.morales.lopez@gmail.com.

El autor agradece profundamente a los dos árbitros anónimos de Estudios Públicos, a Alejandra Corvalán Helbig, a Pablo Torres Villalobos y a Bernardita Piedrabuena Keymer por sus valiosos comentarios formulados a una versión preliminar de este artículo. 


\title{
THE FINANCIAL MARKET COMMITTEE: A SHIFT IN CHILE'S FINANCIAL SUPERVISION ARCHITECTURE
}

\begin{abstract}
Law 21000, enacted in February 2017, created the Financial Market Committee and was intended to modernize the Chilean system of financial supervision. In this context, it held out a major promise: the integration into a single body of the Superintendency of Securities and the Superintendency of Banks and Financial Institutions. Combining the two superintendencies into the Committee will bring a momentous change in the way financial regulation is conceived in Chile. This article aims to set out the reasons behind the decision to consolidate our system of supervision into a single body and the major implications arising from the institutional design of the new regulator.
\end{abstract}

Keywords: Financial Market Committee; financial supervision; financial regulation; financial supervision architecture.

RECEIVED: April 2018; ACCEPTED: May 2018.

\section{INTRODUCCIÓN}

$E^{\prime}$ n sociedades modernas hipercomplejas el buen desempeño del mercado financiero, su estabilidad y la confianza que depositamos en su adecuado funcionamiento resultan cruciales para mantener una economía real robusta y dinámica. Ahora bien, el tiempo se ha encargado de recordarnos su inherente fragilidad. Las instituciones financieras son vulnerables en tanto mantienen estructuras de capital inestables, ${ }^{1}$ los mercados en que participan se encuentran altamente interconecta$\operatorname{dos}^{2} \mathrm{y}$, por tanto, expuestos a evidentes riesgos de contagio ante shocks

${ }^{1}$ La intermediación financiera posee una relación capital-deuda muy inferior a la mayoría de las actividades productivas y se encuentra expuesta a fuertes desajustes entre activos y pasivos en una dimensión temporal dinámica. Hyman P. Misky, Stabilizing an Unstable Economy (Nueva York: MacGraw Hill, 2008). Para una explicación simple de la dinámica de capital, deudas y préstamos en la industria bancaria, véase Anat Admati y Martin Hellwig, The Bankers' New Clothes: What's Wrong with Banking and What to Do about it (Princeton: Princeton University Press, 2013), capítulos 2 y 3.

2 Para comprender la naturaleza de los riesgos sistémicos, véase Brunnermeier et al., "The Fundamental Principles of Financial Regulation", Geneva Reports on the World Economy 11 (2009), capítulo 2. 
o pérdidas de confianza. ${ }^{3}$ Dichas características, aumentan considerablemente los riesgos de corridas o rupturas en la cadena de pagos, las que se materializan muy rápidamente. ${ }^{4}$

Hoy resulta evidente que el daño que generan las crisis financieras es enorme y excede con creces el costo privado que ha de ser soportado por las instituciones que pudieron haberlas iniciado. ${ }^{5}$ En efecto, dichos costos son amplificados por los niveles de interconexión e interdependencia existentes. Así las cosas, resulta absolutamente imprescindible contar con un diseño regulatorio que facilite su correcta supervisión.

En virtud de lo anterior, y luego de las últimas crisis financieras, numerosos países han iniciado instancias de revisión de sus modelos de supervisión y se han generado interesantes reformas en la arquitectura de los mismos. ${ }^{6}$ Chile recientemente se ha sumado a este proceso de revisión con la dictación de la Ley 21.000, que crea la Comisión para el Mercado Financiero.

Al diseñar u optar por un determinado modelo de supervisión se busca maximizar las posibilidades de que los organismos competentes promuevan la innovación y el desarrollo del mercado; mantengan su adecuado funcionamiento en tiempos de normalidad; detecten tempranamente hipótesis de riesgo, y reaccionen con agilidad ante el surgimiento de eventos críticos. ${ }^{7}$

El modelo de supervisión por silos o industrias empleado en Chile nos ha permitido soportar razonablemente bien el impacto de las crisis financieras globales. No obstante, acontecimientos recientes han puesto en evidencia numerosas falencias: ${ }^{8}$ (i) falta de independencia y auto-

${ }^{3}$ Véase John Armour, "Bank Resolution Regimes: Designing the Right Model?" (2010), 1.

${ }^{4}$ Véase G. Davies y M. Dobler, "Bank resolution and Safeguarding the Creditors Left Behind", Bank of England Quarterly Bulletin Q3 (2011), 1.

${ }^{5}$ Véase Brunnermeier et al., "The Fundamental Principles".

${ }^{6}$ Group of Thirty, The Structure of Financial Supervision: Approaches and Challenges in a Global Marketplace, Washington, 2008, 12 y ss. Para algunas consideraciones acerca del aumento incremental de la regulación financiera luego de haberse detectado un fraude o gatillado una crisis financiera, véase Brunnermeier et al., "The Fundamental Principles", capítulo 1.

${ }^{7}$ Davies y Dobler, Bank Resolution.

${ }^{8}$ Véase Cámara de Diputados, "Informe de la comisión investigadora de la actuación de los organismos públicos competentes en relación al eventual fraude de empresas de inversión", de 15 de septiembre de 2016, y que versaba principalmente sobre los casos denominados "AC Inversions", "IM Forex" e "Investing Capital", 75 y siguientes. 
nomía de los supervisores; (ii) débil ejercicio de sus potestades normativas; (iii) posibilidades de arbitrajes regulatorios, con el subsecuente riesgo aparejado a la banca en las sombras y a otras actividades que se sitúan en puntos ciegos de supervisión; ${ }^{9}$ (iv) descoordinación regulatoria; (v) imposibilidad de supervisar conglomerados, ${ }^{10}$ lo que se traduce en una carencia de visión sistémica y de riesgos consolidados, y (vi) reclamos recurrentes sobre vulneración del debido proceso. ${ }^{11}$

En ese contexto, la dictación de la Ley 21.000 permitirá mejorar la posición en que se encontrarán los organismos competentes para desarrollar una adecuada supervisión y responder con agilidad ante hipótesis de riesgo financiero.

Si bien la mayoría de los expertos han considerado que la integración de ambos organismos en una comisión constituirá un avance respecto del actual sistema de supervisión, al mismo tiempo han sostenido que hubiese sido más razonable migrar hacia un esquema de twin peaks. Este artículo pretende demostrar que dicha solución no es evidente y que existen relevantes argumentos para defender la opción de pasar a un modelo semi integrado de supervisión.

${ }^{9}$ Tales problemas se encontrarían asociados a la forma en que se delimita el perímetro regulatorio de los organismos supervisores. Para un análisis más detallado, véase G. Lambeth y D. Morales, "La Comisión para el Mercado Financiero y el perímetro regulatorio del regulador: algunas notas sobre sus implicancias", Anuario de Derecho Público 1 (2017): 241-266.

${ }^{10}$ El Comité de Basilea de Supervisión Bancaria y el Joint Forum definen como conglomerados financieros a "cualquier grupo de compañías que se encuentren bajo un control común y cuyas actividades exclusivas o principales consistan en prestar servicios en al menos dos sectores financieros diferentes". Tripartite Group of Bank, Securities and Insurance Regulators, The Supervision of Financial Conglomerates, 1995.

${ }^{11}$ Véanse, por ejemplo, la sentencia del Tribunal Constitucional, recaída en la causa Rol 2922-15, del 29 de septiembre de 2016, en la que se declaró la inaplicabilidad por inconstitucionalidad del artículo 29 del Decreto Ley 3.538; la resolución de la Corte de Apelaciones de Santiago, recaída en la causa Rol 1963-15, en la que se declaró la vulneración del principio de ne bis in ídem por haberse impuesto sanciones en sede penal y administrativa por infracciones que vulneraban idéntico bien jurídico protegido, y la resolución de la Corte de Apelaciones de Santiago, recaída en la causa Rol 644-2016, de fecha 31 de agosto de 2016, que declaró que el procedimiento seguido por la Superintendencia de Bancos en contra de Corpbanca S.A. no había satisfecho estándares mínimos de debido proceso. 


\section{EL PROPÓSITO DE LA REGULACIÓN DEL MERCADO FINANCIERO}

En general, se sostiene que los objetivos de la regulación financiera se relacionan con la necesidad de (i) evitar abusos de poder de mercado; (ii) prevenir que agentes sofisticados exploten las ventajas que mantienen respecto de los consumidores financieros y del público general - asimetrías de información - , y (iii) resolver, en la medida de lo posible, las externalidades negativas de la industria. ${ }^{12}$ Es común que la misión de impedir abusos de poder de mercado sea encomendada a los organismos encargados de la promoción general de la competencia, mientras que las autoridades que deben velar por el correcto desempeño del mercado financiero concentran sus esfuerzos en los objetivos (ii) y (iii). ${ }^{13}$

Las principales fallas de mercado con que han de lidiar los organismos encargados de la supervisión financiera - externalidades negativas $^{14} \mathrm{y}$ asimetrías de información - tienen un correlato directo en la estructuración de sus dos preocupaciones centrales: la estabilidad del sistema financiero, por una parte, y la preocupación por su adecuado funcionamiento a través de la protección de inversionistas y consumidores financieros, por la otra. ${ }^{15}$

La literatura sobre la materia suele utilizar los términos de regulación prudencial, para referirse a la preocupación por la estabilidad sistémica, y de regulación conductual, para aludir al objetivo de velar porque las conductas de los agentes de mercado satisfagan determinados estándares de honestidad y justicia. ${ }^{16}$ En ese contexto, y dada la relevancia que tendrá dicha distinción en la discusión actual sobre esquemas de supervisión, explicaremos brevemente las preocupaciones principales de uno y otro tipo de regulación.

${ }^{12}$ Charles Goodhart, "Some Regulatory Concerns; and An Incentive Structure for Financial Regulation", Swiss Journal of Economics and Statistics (SJES) 132, n. ${ }^{\circ} 4$ 1996), 614.

${ }^{13}$ Ibídem, 615.

${ }^{14}$ A. Kern, "Bank Resolution Regimes: Balancing Prudential Regulation and Shareholder Rights", Journal of Corporate Law Studies 9, n. ${ }^{\circ} 1$ (2009), 225; V. Acharya, "A Theory of Systemic Risk and Design of Prudential Bank Regulation", Journal of Financial Stability 5, n. ${ }^{\circ} 3$ (2009), 225-226.

${ }^{15}$ Goodhart, "Some Regulatory Concerns", 615.

${ }^{16}$ M. Taylor, “Twin Peaks': A Regulatory Structure for the New Century”, Centre for the Study of Financial Innovation, 1995; Goodhart, "Some Regulatory Concerns". 


\subsection{Regulación prudencial}

La regulación prudencial tiene por objetivo hacerse cargo de los riesgos sistémicos; esto es, aquellos que pudieren afectar el funcionamiento del mercado financiero en su conjunto. ${ }^{17}$ Dichos riesgos son endógenos a las estructuras modernas del mercado financiero ${ }^{18}$ y no pueden ser correctamente aprehendidos a partir de la supervisión aislada de entidades financieras. ${ }^{19}$ Esta imposibilidad se manifiesta especialmente cuando la supervisión se encuentra basada en esquemas estáticos o con un enfoque marcadamente retrospectivo. ${ }^{20}$ En la actualidad, lidiar con los riesgos del mercado financiero exige la capacidad de efectuar una supervisión amplia y adaptable, capaz de entender y de medir los riesgos consolidados de la industria, ${ }^{21}$ así como de reaccionar con agilidad ante el surgimiento de nuevas actividades o riesgos. ${ }^{22}$

Los riesgos sistémicos se asocian, en general, con: (i) la solvencia y liquidez de determinadas entidades financieras; ${ }^{23}$ (ii) el resguardo de la cadena de pagos, ${ }^{24}$ y (iii) la estabilidad del mercado financiero completo. ${ }^{25}$ En este contexto, se sostiene que las instituciones que revisten relevancia sistémica son aquellas que, prescindiendo de su naturaleza o

${ }^{17}$ Acharya, A Theory of Systemic, 224.

${ }^{18}$ S. Claessens y L. Kodres, "The Regulatory Responses to the Global Financial Crisis: Some Uncomfortable Questions”, IMF Working Paper 14/46 (2014), 4.

${ }^{19}$ Ibídem.

${ }^{20}$ Ibídem. Sobre la importancia de que el derecho público y el Estado tengan un marcado compromiso con el futuro, véanse P. Nonet y P. Selznick, Law and Society in Transition: Toward Responsive Law (New Jersey: Transaction Publishers, 1978), y S. Montt, “Autonomía y responsividad: dos expresiones de la vocación juridificadora del derecho administrativo y sus principios fundamentales", Centro de Regulación y Competencia, 2010. Para un argumento similar en materia de supervisión financiera, véase Nobuchika Mori, From Static Regulation to Dynamic Supervision: Speeches by Commissioner Nobuchika Mori (Tokyo: Financial Services Agency of Japan, 2017).

${ }^{21}$ La discusión acaecida en el contexto de la preparación de la Dodd-Frank Act en Estados Unidos, y que culminó con una forma flexible de atribución de competencias para los reguladores financieros, puede ser especialmente ilustrativa sobre el particular.

22 Resulta probable que el desarrollo de actividades relacionadas con tecnología financiera incremente las exigencias de velocidad adaptativa hacia el futuro.

${ }^{23}$ Véase M. Dewatripont y J. Tirole, The Prudential Regulation of Banks (Cambridge, Mass: MIT Press, 1994), 5 y 35.

${ }^{24}$ Goodhart, "Some Regulatory Concerns", 622.

${ }^{25}$ Ibídem. 
actividad, pueden generar problemas en el sistema en caso de presentar signos individuales de inestabilidad. Ello puede ocurrir en virtud de su tamaño, de su nivel de interconexión o en razón de ofrecer productos esenciales - e insustituibles - para determinados actores relevantes. Las entidades que cuentan con estas características se ven expuestas a la aparición de riesgo moral, en los términos que explicaremos luego.

Las instituciones de relevancia sistémica comparten algunas características relevantes: elevados niveles de riesgo a que se encuentran expuestos los derechos de sus depositantes o mandantes; la dispersión de sus titulares, y la inexistencia de representantes privados que desempeñen funciones adecuadas de control. ${ }^{26}$ Estas características corresponden paradigmática pero no exclusivamente a las empresas bancarias. ${ }^{27}$

La justificación de la regulación prudencial se explica por la necesidad de proteger a pequeños depositantes expuestos a riesgos relevantes; de velar por la continuidad del sistema de pagos, y de mantener la estabilidad del sistema financiero, procurando evitar contagios. ${ }^{28}$ En general, se sostiene que la necesidad de intervención estatal se explica por la existencia de condiciones que impiden un desempeño eficiente de los mercados y que dificultan el surgimiento de soluciones privadas. Los problemas que se presentan son principalmente de opacidad, complejidad e incertidumbre, por una parte, y de riesgo moral, por la otra. ${ }^{29}$

\subsubsection{Opacidad, complejidad e incertidumbre}

Los depositantes, para garantizar que sus fondos sean adecuadamente administrados, debiesen desarrollar una gran variedad de funciones de fiscalización y auditoría de las entidades en las que confían su dinero, pero en los hechos no lo hacen ni se encuentran en una posición que haga razonable exigírselos. ${ }^{30}$

${ }^{26}$ Dewatripont y Tirole, The Prudential Regulation, 35.

${ }^{27}$ Ibídem, 8 y 87 . De hecho, la crisis subprime fue causada, principalmente, por entidades no bancarias. Véase M. Taylor, “'Twin Peaks' Revisited... A second chance for regulatory reform", Centre for the Study of Financial Innovation, 2009,5 .

${ }^{28}$ Goodhart, "Some Regulatory Concerns", 620.

${ }^{29}$ Véase el capítulo 2 de Dewatripont y Tirole, The Prudential Regulation.

${ }^{30}$ Ibídem, 31. 
Ello, porque: (i) resulta ineficiente la duplicación del esfuerzo de recopilación y análisis de datos por una multiplicidad de agentes económicos dispersos; ${ }^{31}$ (ii) la labor no genera suficiente utilidad marginal para cada depositante como para incentivarlo a controlar adecuadamente a su mandatario ${ }^{32}$ —además, la información es un bien público, por lo que tiende a ser producida en cantidades subóptimas-; (iii) las actividades de monitoreo son complejas, caras y exigentes en términos de tiempo, ${ }^{33}$ y (iv) los depositantes cuentan con un escaso grado de sofisticación, lo que los sitúa en una posición de desventaja con la entidad depositaria. ${ }^{34}$ En este contexto, la intervención pública se explica, primero, por la necesidad de ofrecer a los pequeños depositantes un servicio de representación que el mercado no provee espontáneamente. ${ }^{35}$

Por otra parte, los riesgos de contagio y de corridas bancarias han sido explicados a partir de diversos factores marcados por la opacidad acerca de la situación de cada compañía y la forma en que maneja sus negocios, así como de los niveles de complejidad de la industria en términos agregados. Ambos fenómenos profundizan los problemas de asimetrías de información y favorecen la adopción de decisiones irracionales. ${ }^{36}$

La incertidumbre existente en torno a la situación de las compañías financieras se encuentra marcada especialmente por la dificultad existente para valorizar sus activos. Escenarios de complejidad financiera pueden traer aparejada una reducción en la percepción de valor de los activos de la entidad en problemas, lo que tiende a agravar la crisis inicial. Además, en virtud de la opacidad presente en la industria, puede generarse la idea de que otros bancos y entidades se encuentran en una situación igualmente compleja, debido a que presumiblemente contarán

${ }^{31}$ Ibídem.

32 Ibídem, 32.

33 Ibídem, 31.

34 Goodhart, "Some Regulatory Concerns"; Dewatripont y Tirole, The Prudential Regulation, 44.

${ }^{35}$ Dewatripont y Tirole, The Prudential Regulation, 35 y 44.

${ }^{36}$ Mathias Dewatripont y Xavier Freixas, "Bank Resolution: A Framework for the Assessment of Regulatory Intervention", Oxford Review of Economic Policy 27, n. ${ }^{\circ} 3$ (2011): 411-436. 
con una cartera de inversiones o de activos similar, ${ }^{37} \mathrm{o}$, bien, se encontrarán suficientemente interconectados con las entidades en riesgo.

Todos esos factores minimizan las posibilidades de que los inversionistas, depositantes y las propias autoridades comprendan adecuadamente los riesgos e imposibilitan que efectúen una labor eficiente de monitoreo del comportamiento de sus mandatarios y supervisados, respectivamente.

\subsubsection{Riesgo moral ${ }^{38}$}

Una situación crítica en materia de estabilidad financiera puede forzar al Estado a intervenir de manera urgente, probablemente con pocas alternativas disponibles y con fuertes presiones para evitar que la crisis se expanda. La inestabilidad y, en el extremo, la caída de entidades financieras producen una reducción de los fondos disponibles en la economía y, por tanto, de los niveles de inversión ${ }^{39}$ y consumo. La contracción de la oferta de fondos, a su vez, podría generar un aumento en las tasas de interés de equilibrio, impactando en la rentabilidad de los bancos y agudizando el problema. ${ }^{40}$ Para evitar que estos efectos sigan expandiéndose, suelen activarse garantías, costearse salvatajes financieros, disminuirse las tasas de interés, etcétera. Ello, puede dar lugar a una injusta transferencia de recursos desde los contribuyentes hacia las instituciones financieras afectadas. ${ }^{41}$

Dichos mecanismos de intervención acrecientan el riesgo moral y de comportamientos oportunistas de las entidades financieras. ${ }^{42} \mathrm{Si}$ los actores del mercado internalizan en su comportamiento estratégico que son firmas demasiado grandes, relevantes o interconectadas como para

${ }^{37}$ Goodhart, "Some Regulatory Concerns", 620-623.

${ }^{38}$ El concepto de "riesgo moral" es utilizado para referirse a situaciones en que los individuos tenderán a emplear un nivel de diligencia menor al deseable, puesto que las consecuencias negativas de sus actuaciones serán cubiertas, al menos en parte, por un tercero. Véase K. J. Arrow, Essays in the Theory of Risk-Bearing (Amsterdam-London: North-Holland, 1970).

${ }^{39}$ Acharya, "A Theory of Systemic", 226.

${ }^{40}$ Ibídem.

${ }^{41}$ Dewatripont y Freixas, "Bank Resolution".

${ }^{42}$ Ibídem, 411-412; Acharya, "A Theory of Systemic", 226; Daniel Tarullo, "Rethinking the Aims of Prudential Regulation". En Bank Structure Conference, Federal Reserve Bank of Chicago (2014), 2. 
que el Estado se encuentre dispuesto a dejarlas caer, dichas firmas estarán dispuestas a tomar más riesgos de los que resultan eficientes. ${ }^{43} \mathrm{La}$ adopción de mayores riesgos generará beneficios privados para la institución financiera que decide tomarlos y en caso de que se genere una situación crítica serán sus aseguradores o los contribuyentes quienes deberán asumir el costo del salvataje. ${ }^{44}$

En virtud de lo anterior, también existe una preocupación relevante de la regulación prudencial para generar mecanismos tendientes a corregir dicho riesgo moral: mejoras en materia de gobiernos corporativos, incentivos adecuados para mitigar una excesiva tendencia al riesgo (por ejemplo, requerimientos de capital), ${ }^{45}$ formas de control de tasas de interés, ${ }^{46}$ mecanismos adecuados de resolución de entidades financieras en problemas ${ }^{47}$ o la inclusión de una carga impositiva especial para las instituciones de relevancia sistémica. ${ }^{48}$

En este contexto, las autoridades encargadas de la supervisión prudencial deberán privilegiar actuaciones preventivas y, de vez en cuando, dejar caer a determinadas entidades financieras: el riesgo de quiebra debe ser lo suficientemente creíble como para neutralizar —al menos en parte- el riesgo moral.

Cabe recordar que las amenazas a la estabilidad del sistema financiero ya no provienen únicamente de la actividad bancaria tradicional. En virtud de ello, se ha insistido sobre la necesidad de contar con herramientas adecuadas para el manejo de eventos $\operatorname{críticos}^{49}$ y capturar todas las hipótesis relevantes de riesgo. Esto último, en ocasiones, exigirá flexibilizar la forma de determinación del perímetro regulatorio de los supervisores financieros, cuestión sobre la que no podremos detenernos aquí. $^{50}$

${ }^{43}$ Dewatripont y Freixas, "Bank Resolution".

${ }^{44}$ Hellmann et al. "Liberalization, Moral Hazard in Banking, and Prudential Regulation: Are Capital Requirements Enough?", The American Economic Review 90, n. ${ }^{\circ} 1$ (2000): 148 .

45 Ibídem.

${ }^{46}$ Ibídem.

${ }^{47}$ Dewatripont y Freixas, "Bank Resolution"; Financial Stability Board, Key Atributes of Effective Resolution Regimes for Financial Institutions, 2014.

48 Taylor, "'Twin Peaks' Revisited”, 6 y 15.

${ }^{49}$ Financial Stability Board, Key Atributes.

50 Tarullo, "Rethinking the Aims". Para un análisis del problema en Chile, véase Lambeth y Morales, "La Comisión para el Mercado". 


\subsection{La regulación conductual}

La regulación conductual se encuentra encargada de velar por el adecuado comportamiento de los agentes del mercado financiero, de modo de garantizar que las transacciones satisfagan estándares mínimos de honestidad y justicia. ${ }^{51}$ Dicha preocupación en los sistemas jurídicos modernos resulta relativamente anómala.

El liberalismo económico valora los intercambios porque los entiende como mutuamente beneficiosos. En ellos, las partes ceden algo, que valoran menos que su contraparte, a cambio de algo que valoran más. ${ }^{52}$ Luego de una transacción voluntaria ambas partes se encontrarían en mejor posición, toda vez que, si el contrato no fuese beneficioso para una de ellas, ésta simplemente se negaría a consentirlo, de forma tal que primaría la inercia. ${ }^{53}$

De este modo, la honestidad y justicia de un determinado contrato se deriva, por regla generalísima, de la mera voluntariedad. La pregunta acerca de la justicia material del intercambio resulta irrelevante para el derecho en tanto asume - como San Mateo - que ella vendría dada por añadidura (Mateo 6:33). Si el contrato ha sido celebrado entonces es, para todos los efectos jurídicamente relevantes, justo.

Ahora bien, desde la época de la codificación a la fecha, han aparecido relevantes subáreas del derecho que introducen principios formativos que exigen el establecimiento de correctivos a la autonomía de la voluntad. Ello resulta patente en el derecho laboral, en el de protección del consumidor o en la regulación de ciertas actividades económicas que mantienen alguna dimensión de interés público o son consideradas riesgosas. La justificación que se ofrece para la introducción de este tipo de correctivos, en general, dice relación con la existencia de fallas de mercado, riesgos o motivos de interés público. La presencia de tales características vuelve difícil que la estructura del derecho privado de contratos haga probable el desempeño de su función: que los intercambios entre particulares se materialicen en términos equitativos y

${ }^{51}$ Taylor, “"Twin Peaks': A Regulatory Structure”; Goodhart, "Some Regulatory Concerns".

${ }^{52}$ R. Epstein, Reglas simples para un mundo complejo (Lima: Pontificia Universidad Católica del Perú, 2005), 97-101.

${ }^{53}$ R. Posner, "Utilitarianism, Economics, and Legal Theory", The Journal of Legal Studies 8, n. ${ }^{\circ} 1$ (1979): 114. 
razonables ${ }^{54}$ Así, resulta crucial responder por qué se justificaría contar con una regulación conductual que busque proteger a inversionistas y consumidores financieros. ${ }^{55}$

En general, se argumenta que respecto de determinado tipo de inversionistas y consumidores financieros - demasiado pequeños, inexpertos o mal informados - se requieren remedios para corregir situaciones de: (i) fraude o abuso; (ii) problemas de agencia, o (iii) ejecución deficiente del mandato. ${ }^{56}$

i) Fraudes y abusos: El sector financiero se encuentra particularmente expuesto a riesgos de fraude, en virtud de que los contratos que se celebran implican, en general, la entrega de dinero en un determinado momento bajo la promesa y expectativa de que éste será regresado en el futuro, si todo sale bien, con algún margen de ganancia. Lo anterior implica que es difícil que quien entrega el dinero inspeccione detenidamente el servicio que recibirá con anterioridad a la celebración del contrato ${ }^{57}$ o efectúe el pago luego de que el servicio haya sido prestado satisfactoriamente — como podría ocurrir en mercados más simples-. Por otra parte, resulta también complejo diferenciar una hipótesis de malos resultados debido a circunstancias de mercado respecto de otra en que existe un comportamiento inadecuado o impropio del mandatario. Esta especial forma de funcionamiento explica la relevancia de la confianza y fe pública involucrada en el mercado financiero. ${ }^{58}$

ii) Problemas de agencia: Los problemas de agencia surgen cuando existe un vínculo contractual en virtud del cual el bienestar de una parte (el mandante o principal) depende de las acciones tomadas por la otra (el mandatario o agente) y, por lo tanto, han de buscarse mecanismos o estructuras que hagan probable que el segundo actúe en el interés

${ }^{54}$ Para una relevante disquisición sobre cómo el derecho permite dotar a la sociedad de determinadas estructuras que hacen probable lo que en ausencia de ellas es improbable, véase F. Atria, La forma del derecho (Madrid: Marcial Pons, 2016), 133 y siguientes.

${ }^{55}$ Goodhart, "Some Regulatory Concerns", 618.

${ }^{56}$ Para tales efectos, seguiremos de cerca el ya citado Goodhart, "Some Regulatory Concerns".

${ }^{57}$ De todos modos, esta forma de funcionamiento es observable en un gran número de mercados y contratos en que el cumplimiento de las obligaciones es diferido en el tiempo.

${ }^{58}$ Goodhart, "Some Regulatory Concerns", 618. 
del primero. ${ }^{59}$ En el contexto del mercado financiero, los problemas de agencia aparecen con frecuencia debido a que el dinero es aportado por el mandante, pero la decisión sobre su utilización es, en muchas ocasiones, tomada por el mandatario. Con ello, el agente puede verse tentado a emplearlo en beneficio propio, alejándose de su compromiso de honrar el interés del principal. ${ }^{60}$

iii) Asesoría o ejecución deficiente del mandato: En este caso no existe un comportamiento deliberadamente autointeresado ni un ánimo del mandatario de perjudicar al mandante. Más bien, se observa un problema relacionado con el nivel de diligencia desplegado en la ejecución del encargo, el que puede ser prestado en términos negligentes o poco disciplinados. ${ }^{61}$ Este tipo de problemas son difíciles de controlar cuando, debido a la complejidad del mandato y la especialización del mandatario, el mandante no está en condiciones de observar el nivel de diligencia con que se ejecuta el encargo.

Todo lo anterior, pone en entredicho el presupuesto en virtud del cual son las partes las que se encuentran en la mejor posición para juzgar la conveniencia y justicia de un contrato, en los términos explicados. Así, el mercado financiero se caracteriza por ciertos elementos que permiten presumir que el derecho privado no será una estructura capaz de desempeñar satisfactoriamente su función; esto es, hacer probable que la voluntariedad sea un buen indicador de la equidad y justicia material de los intercambios. ${ }^{62}$ Como respuesta a ese problema, surge la necesidad de la supervisión conductual.

\section{LOS MODELOS DE SUPERVISIÓN}

\subsection{La relevancia de los modelos de supervisión}

El problema de la estructura institucional de la regulación financiera se ha transformado en un asunto de relevancia mundial y se ha tomado

59 J. Armour et al., "Agency Problems, Legal Strategies, and Enforcement", Oxford Legal Studies Research Paper n. ${ }^{\circ} 21$ (2009).

${ }^{60}$ Goodhart, "Some Regulatory Concerns", 618-619.

${ }^{61}$ Ibídem, 619.

${ }^{62}$ Atria, La forma. 
el debate público de numerosos países.$^{63}$ Ello, porque — con cierta probabilidad - la elección de un diseño institucional adecuado permitirá supervisar satisfactoriamente el mercado financiero y, a su vez, facilitar la adopción de respuestas ágiles, flexibles y prospectivas. ${ }^{64}$

La relevancia de una regulación y supervisión financiera adecuada es innegable: un sistema financiero estable tiene una poderosa influencia en el desarrollo económico de un país completo, y un bien estructurado régimen regulatorio contribuye al correcto funcionamiento del mismo. ${ }^{65}$ De este modo, y sin importar el diseño institucional por el que se opte, el sistema de supervisión debiese cubrir, al menos, los siguientes tópicos principales: ${ }^{66}$ (i) definición de la política monetaria; (ii) mantención de la integridad de la cadena de pagos; (iii) regulación y supervisión prudencial; (iv) regulación y supervisión conductual; (v) manejo de redes de seguridad y garantías estatales; (vi) regularización temprana de entidades en riesgo; y, (vii) resolución de entidades financieras en casos críticos.

A pesar del relativo consenso existente sobre la necesidad de hacerse cargo de dichas tareas, no hay acuerdo sobre la forma en que éstas deben distribuirse en el entramado institucional de cada país. Ello, en virtud de que la elección de un determinado modelo institucional de supervisión exige necesariamente balancear una serie de trade-offs $\mathrm{y}$, por tanto, optar por cualquier diseño nos obliga a soportar como contrapartida algunos defectos. Como señala Elizabeth Brown, "ninguna nación ha ideado una estructura regulatoria perfecta para abordar los riesgos que plantean los servicios financieros". ${ }^{67}$ Ello explica la falta

63 Véase, por ejemplo, M. Taylor y A. Fleming, "Integrated Financial Supervision: Lessons of Northern European Experience", Policy Research Working Paper Series 2223 World Bank (1999); David Llewellyn, "Institutional Structure of Financial Regulation and Supervision: The Basic Issues", en World Bank Seminar Aligning Supervisory Structures with Country Needs, Washington DC, 6th and 7th June, 2006.

${ }^{64}$ En el mismo sentido, por ejemplo, C. Briault, "The Rationale for a Single National Financial Services Regulator", UK, FSA Occasional Paper Series 16 (2002).

${ }^{65}$ Llewellyn, "Institutional Structure", 5.

${ }^{66}$ Llewellyn, "Institutional Structure", 5-6.

${ }^{67}$ E. Brown, "Consolidated Financial Regulation: Six National Case Studies and the Experience of the European Union", The Volcker Alliance. Working for Effective Government, 2015, 113. Ver también Llewellyn, "Institutional Structure", 13; y, M. Taylor y R. Abrams, "Issues in the Unification of Financial Sector Supervision”, International Monetary Fund. Working Paper 00/213, (2000): 27. 
de convergencia internacional en la materia. La revisión de experiencia comparada muestra la existencia de una amplia variedad de estructuras institucionales posibles. ${ }^{68}$

Así, algunos países han optado por mantener esquemas de agencias múltiples y diferenciadas por industrias — silos—; 99 otros han atribuido competencias en virtud de las funciones de las actividades, instrumentos y vehículos financieros que los reguladores deben supervigilar - funcionales-; otros han creado un único organismo encargado de la supervisión financiera completa - integrados-, o, bien, han generado instituciones separadas para encargarse de la supervisión prudencial y conductual — twin peaks - . Además, al interior de cada familia de modelos de arreglos institucionales existen numerosos matices y es posible apreciar diferencias considerables al mirar de cerca sus particularidades. "Las diferencias a nivel nacional reflejan múltiples factores: evolución histórica, la estructura del sistema financiero, las estructuras y tradiciones políticas, y el tamaño del país y de su sector financiero", señala D. T. Llewellyn. ${ }^{70}$

Los esquemas institucionales de cada país, en general, se encuentran determinados por la respuesta ofrecida a tres preguntas centrales: $:^{71}$ (i) ¿las agencias encargadas de la supervisión financiera deben tener una visión holística o deben especializarse en un determinado sector?; (ii) ¿qué rol desempeñará el Banco Central en materia de supervisión?, y (iii) ¿la supervisión conductual debe ser desarrollada por una agencia especialmente dedicada a ello o sus funciones pueden radicarse en los mismos organismos encargados de la supervisión prudencial?

La forma en que se responda a dichas interrogantes indicará el tipo de modelo institucional que se ha elegido implementar. Con todo, cabe tener presente que, si bien un adecuado diseño institucional puede mejorar las posibilidades de actuación de los organismos supervisores, y ello puede tener por consecuencia un mejor funcionamiento del mercado financiero, D. T. Llewellyn nos recuerda que "es una ilusión

68 C. Goodhart et al., Financial Regulation: Why, How and Where Now? (Londres y Nueva York: Routledge, 1998); Llewellyn, "Institutional Structure”; J. de Luna Martínez y T. Rose, "International Survey of Integrated Financial Sector Supervision”. Policy Research Working Paper 3096, World Bank (2003).

${ }^{69}$ Llewellyn, "Institutional Structure".

${ }^{70}$ Ibídem, 35.

${ }^{71}$ Ibídem, 3. 
creer que una estructura es perfecta o garantiza una regulación y supervisión efectiva y eficiente del sistema financiero. Cambiar la estructura institucional de la regulación no puede ser nunca visto como la panacea, o como un sustituto de una efectiva y eficiente regulación y supervisión". ${ }^{72}$ En ese sentido, las reglas del juego que se establezcan en concreto y la prolijidad con que se desempeñen las tareas de supervisión, fiscalización y sanción jugarán un rol fundamental en el adecuado funcionamiento del mercado.

Habiendo dicho esto, en el apartado siguiente explicaremos brevemente - $\mathrm{y}$ valiéndonos de una simplificación extrema- las primordiales características de las cuatro principales familias de diseños institucionales de arquitectura de la supervisión.

\subsection{Las cuatro familias de modelos de arquitectura de la supervisión financiera ${ }^{73}$}

\subsubsection{Los modelos institucionales, por silos o industrias}

El modelo de silos constituye el enfoque tradicional de supervisión $^{74}$ — que se encuentra, con matices, aún vigente en Chile- y que fija el perímetro regulatorio de cada organismo supervisor, atendiendo a la naturaleza jurídica de las entidades fiscalizadas. ${ }^{75}$

Este enfoque institucional se basa en la premisa de que existen distinciones relativamente claras entre cada línea de negocios y los productos ofrecidos son fácilmente categorizables. ${ }^{76}$ Las ventajas asociadas a un modelo de silos tendrían relación con mayores niveles de especialización del regulador en una determinada industria.

72 Ibídem, 7.

${ }^{73}$ Group of Thirty, The Structure, 13 y ss.; M. Larraín, "Notas al último intento de reforma del sistema de supervisión financiera", Anuario de Derecho Público 1 (2012), 392-414, 405 y ss. También J. Desormeaux et al., Informe final: Comisión de reforma a la regulación y supervisión financiera, 2011. La explicación ofrecida en este acápite descansa ostensiblemente en dichas fuentes.

${ }^{74}$ Group of Thirty, The Structure, 13; H. M. Schooner y M. Taylor, "United Kingdom and United States Responses to the Regulatory Challenges of Modern Financial Markets". Texas International Law Journal 38, n. ${ }^{\circ} 2$ (2003): 318.

${ }^{75}$ Utilizan este esquema en la actualidad, entre otros, México, Hong Kong y China.

${ }^{76}$ Schooner y Taylor, "United Kingdom”, 318. 
Ahora bien, esta estructura de supervisión se habría vuelto subóptima, en opinión de los expertos, dada la evolución actual de los mercados en buena parte del mundo. Los límites existentes entre cada industria se han ido desdibujando progresivamente, tanto por el surgimiento de nuevos instrumentos mixtos como por la aparición creciente de conglomerados financieros. Así, esta estructura no daría cuenta de la forma en que en la actualidad se desarrollan los mercados financieros.

Otro problema que se cita recurrentemente respecto de estos modelos es que exigen mantener elevados niveles de coordinación entre los distintos organismos supervisores, ${ }^{77}$ debiendo soportarse los costos de transacción correlativos, disparidades de criterios y, en ocasiones, su poca disposición para colaborar entre sí.

\subsubsection{Los modelos funcionales}

En los modelos funcionales la supervisión se encuentra determinada por la actividad que realice una entidad específica sin importar su naturaleza jurídica. ${ }^{78-79}$ Los beneficios de los modelos funcionales consisten en la aplicación de reglas consistentes para una determinada actividad, disminuyendo los riesgos de arbitraje regulatorio. ${ }^{80}$

Sin embargo, los sistemas de supervisión basada en funciones enfrentan el problema de que - para ser operativos - requieren que las actividades quepan de forma clara dentro de una categoría de funciones, lo que resulta cada vez más complejo debido al dinamismo del mercado y la aparición de instrumentos financieros mixtos cada vez más sofisticados. ${ }^{81}$ En ese sentido, algunas de las críticas formuladas a los sistemas de silos resultan también aplicables a esquemas funcionales.

En cualquier caso, estos últimos pueden presentar algunas dificultades adicionales, en tanto un criterio de atribución de competencias funcional suele presentar mayores áreas grises. Ello genera riesgos de contiendas de competencia, ${ }^{82}$ de desincentivar la innovación

${ }^{77}$ Group of Thirty, The Structure, 13-14.

${ }^{78}$ Desormeaux et al., Informe, 31.

${ }^{79}$ Utilizan este esquema en la actualidad Brasil y España.

${ }^{80}$ Desormeaux et al., Informe, 52; Larraín, "Notas", 405.

${ }^{81}$ Desormeaux et al., Informe, 52-53; Briault, "The Rationale", 13.

82 E. Brown, "E Pluribus Unum-Out of Many, One: Why the United States Needs a Single Financial Service Agency", University of Miami Business Law Review 14 (2005): 64. 
financiera - por la mayor incertidumbre-, de aumentar los costos de coordinación, ${ }^{83}$ de no permitir que exista una supervisión integrada o sistémica, ${ }^{84}$ de dificultar el monitoreo de riesgos consolidados o de impedir una adecuada supervisión de conglomerados. ${ }^{85}$ Este tipo de modelos, puede, además, generar problemas derivados de actuaciones contradictorias o de interferencia entre organismos, de actuaciones sucesivas, en el mismo sentido, por ausencia de unidad de mando o de inhibición por mutua deferencia. ${ }^{86}$

\subsubsection{Los modelos integrados}

En los modelos de supervisión integrada existe un regulador único para la totalidad del sistema, ${ }^{87}$ por lo que se observa una doble convergencia. Por una parte, su perímetro regulatorio se define en términos amplios sin distinguir por entidades, actividades, funciones o instrumentos. Por la otra, se le encomiendan al supervisor objetivos prudenciales y conductuales.

Las ventajas de este esquema se explican en virtud de que evita la duplicación de esfuerzos ${ }^{88}$ y el surgimiento de conflictos de competencia entre organismos reguladores, limita las hipótesis de arbitraje regulatorio, aporta una mirada sistémica, dota de cierta adaptabilidad al sistema y, además, genera economías de escala y de ámbito en las actividades de supervisión y fiscalización. ${ }^{89}$ Además, ofrece, al menos en principio, una mejor aproximación a la supervisión de conglomerados

${ }^{83}$ Group of Thirty, The Structure, 14.

${ }^{84}$ Desormeaux et al., Informe, 52.

${ }^{85}$ Larraín, "Notas", 405.

86 Para un análisis sobre problemas de coordinación regulatoria en Chile, véase Pardow, "El Servicio Nacional del Consumidor de Chile (Sernac) y los reguladores sectoriales: buscando mecanismos para una mejor coordinación". Revista Economía y Política 2, n. ${ }^{\circ} 2$ (2015): 107-136.

${ }^{87}$ Este modelo ha sido adoptado en Alemania, Austria, Dinamarca, Japón, Malasia, Nueva Zelanda, Singapur, Suecia, Suiza y Finlandia. En Sudamérica es utilizado, con matices, en Bolivia y Colombia.

${ }^{88}$ E. Brown, "A Comparison of the Handling of the Financial Crisis in the United States, the United Kingdom, and Australia", Villanova Law Review 55, n. ${ }^{\circ} 3$ (2010): 512 .

${ }^{89}$ Desormeaux et al., Informe, 53-54. 
financieros ${ }^{90} \mathrm{y}$ a los nuevos esquemas de supervisión basada en riesgos, al manejo de riesgos consolidados en la industria, mientras que evita el surgimiento de criterios disímiles, disfuncionales o abiertamente contradictorios entre dos o más organismos reguladores..$^{91}$

Si bien este enfoque de supervisión puede ser efectivo y eficiente para mercados pequeños, ${ }^{92}$ la experiencia ha permitido corroborar que, en grandes mercados, los sistemas de supervisión integrada tienden a elevar los riesgos de sesgo del regulador ${ }^{93}$ y pueden generar tensiones entre objetivos disímiles que han de ser perseguidos por un mismo órgano. ${ }^{94}$

\subsubsection{Los modelos de regulación por objetivos, de cumbres gemelas o de twin peaks}

Los modelos de regulación por objetivos, de cumbres gemelas o de twin peaks ${ }^{95}$ buscan alcanzar economías de ámbito entre reguladores con objetivos compatibles y disociar las funciones entre las que podría

${ }^{90}$ Larraín, "Notas", 406.

${ }^{91}$ Group of Thirty, The Structure, 14.

92 Ibídem.

${ }^{93}$ Ello, porque no existirá otro servicio que pueda llamar la atención sobre un error, omisión o desprolijidad en la supervisión. Este riesgo disminuye en la medida en que existen más organismos supervisores.

${ }^{94}$ Desormeaux et al., Informe, 53-54; Larraín, "Notas", 406. El problema de concentrar en un mismo órgano objetivos que pueden llegar a colisionar, según algunos, habría llevado al Reino Unido a abandonar un sistema integrado de supervisión. Ello, en virtud de que la Financial Services Authority (FSA) habría privilegiado velar por uno de sus objetivos (conductual) en desmedro del otro (prudencial). Con todo, esta lectura del problema ocurrido en Inglaterra no es pacífica. Elizabeth Brown ha sostenido que la falla pudo deberse a la existencia de captura y de competencia en laxitud entre la agencia británica y los reguladores norteamericanos, mientras ambos buscaban convertirse en el principal centro financiero mundial. Véase Brown, "Consolidated Financial Regulation", 86-89 y Brown, "A Comparison", 528. En el mismo sentido, pero añadiendo que el gobierno inglés habría presionado a la FSA para evitar una regulación que pudiera hacer perder competitividad al Reino Unido como centro financiero mundial, véase Baldwin et al., Understanding Regulation: Theory, Strategy, and Practice (Nueva York: Oxford University Press, 2012), 278. Por otra parte, Taylor ha sostenido que, además, es posible detectar problemas asociados a la falta de claridad en la distribución de roles entre la FSA y el Banco Central inglés. Taylor, “Twin Peaks' Revisited”, 4.

${ }^{95}$ Este modelo de supervisión ha sido implementado en Australia, Italia, Francia, Portugal, Canadá, Holanda y Reino Unido. 
existir tensión. Así, una cumbre se erige como regulador prudencial mientras la otra desarrolla actividades de fiscalización y regulación conductual. ${ }^{96-97} \mathrm{El}$ diseño de este modelo tiene por objeto reunir algunos de los beneficios de la consolidación, mientras intenta evitar los conflictos que pueden surgir entre ambos objetivos. ${ }^{98}$

En los modelos de cumbres gemelas, cuando entran en conflicto ambos objetivos se genera un problema de difícil solución, dado que cada organismo tenderá a privilegiar su propio mandato sacrificando el de la otra cumbre. En estos casos, según algunos expertos, el problema debiese solucionarse en un nivel político. ${ }^{99}$ En opinión de otros, el sistema debiese establecer una regla que favorezca el mandato de carácter prudencial sobre el conductual. ${ }^{100}$ Algunos modelos institucionales, como el del Reino Unido, han optado por entregarle al regulador prudencial la posibilidad de vetar una decisión del regulador conductual cuando ésta pudiese generar inestabilidad financiera. ${ }^{101}$ Ahora bien, en los hechos, lo probable es que, una vez presentado el conflicto, se termine optando por privilegiar - por una ponderación de costos y beneficios asociados - el mandato de estabilidad financiera, sea cual sea la forma en que se estructure el mecanismo de ponderación pertinente. ${ }^{102}$

Las desventajas del modelo de cumbres gemelas se encuentran relacionadas con su implementación: si bien desde un punto de vista teó-

96 Véase, la obra seminal, ya citada: Taylor, “'Twin Peaks': A Regulatory Structure".

${ }^{97}$ El enfoque de cumbres gemelas ha sido recomendado por el Grupo de los 30 en 2009 y una serie de expertos en materia de supervisión bancaria, entre ellos destacan S. Fischer, "Preparing for Future Crises". Conferencia Anual de Jackson Hole, 2009, y M. King, "Speech at the Lord Mayor's Banquet for Bankers and Merchants of the City of London at the Mansion House", 2010. En Chile, véase Desormeaux et al., Informe.

${ }^{98}$ Group of Thirty, The Structure, 14; Desormeaux et al., Informe, 54-58.

99 Taylor, “Twin Peaks': A Regulatory Structure”, 15. En el mismo sentido, véase Goodhart et al. Financial Regulation.

${ }^{100}$ Group of Thirty, The Structure, 14.

${ }^{101}$ Brown, "Consolidated Financial Regulation", 70.

102 En el caso de la caída del Northern Rock en UK, la hipótesis fue inversa. Ello, en opinión de Taylor, resultaba esperable debido a que el mandato conductual es políticamente sensible y los resultados de dichas actividades resultan medibles, a diferencia de los esfuerzos de regulación prudencial. Taylor, "The Road from 'Twin Peaks' and the Way Back", Connecticut Insurance Law Journal 16, n. 1 (2009): 81-82. 
rico su diseño podría parecer comparativamente preferible, su puesta en funcionamiento podría traer aparejados elevados costos de transacción, tanto para los agentes de mercado, que deberán relacionarse con dos autoridades, como para los propios supervisores, que gastarán tiempo y recursos en tratar de actuar coordinadamente.

Por otra parte, en numerosas ocasiones la distinción entre lo prudencial y lo conductual presenta límites difusos y poco operativos como criterio de atribución de competencias. En ese contexto, resulta plausible que algunas de las críticas formuladas a los modelos de silos y funcionales sean, en parte, replicables respecto del esquema de cumbres gemelas.

\subsection{Tendencias a nivel global}

A partir de la explicación anterior, es posible concluir que cada modelo cuenta con relevantes ventajas y debe soportar también algunos costos. Así, la decisión de optar por uno u otro implica necesariamente efectuar un balance pormenorizado de los trade-offs involucrados en cada esquema e intentar predecir qué aproximación resultará más compatible con las características particulares de cada mercado. Esto no constituye un ejercicio simple.

A pesar de ello, en el último tiempo se ha observado una cierta tendencia a nivel global. Los modelos de supervisión basados en supuestos institucionales y funcionales han mostrado ser poco efectivos al momento de fiscalizar actividades desarrolladas por conglomerados e instrumentos financieros cada vez de mayor complejidad. Numerosos países, que habían adscrito a dichos modelos, han desarrollado relevantes procesos de revisión de los mismos. ${ }^{103}$ Por esta razón, la mayoría de los países con mercados financieros robustos han decidido migrar - o se encuentran discutiendo dicha posibilidad - hacia modelos integrados, por una parte, o de twin peaks, por la otra. ${ }^{104}$ Las recomendaciones de los organismos internacionales especializados se dirigen en el mismo sentido. ${ }^{105}$

Este proceso se explicaría porque estos dos últimos sistemas se encontrarían mejor preparados para abordar los problemas relacionados con varios fenómenos concurrentes en la industria financiera: (i) la di-

\footnotetext{
${ }^{103}$ Schooner y Taylor, "United Kingdom", 318.

${ }^{104}$ Brown, “A Comparison”, 512.

${ }^{105}$ Desormeaux et al., Informe, 53; Group of Thirty, The Structure.
} 
fuminación de los límites entre sectores (blurring of the boundaries) ${ }^{106}$; (ii) los niveles de interconexión observables; (iii) el surgimiento de conglomerados, y (iv) la necesidad correlativa de evaluar riesgos consolidados del sistema. ${ }^{107}$ Así, el desarrollo del mercado ha vuelto más difícil supervisar el sector financiero a través de agencias especializadas en un determinado sector o función.

Los fenómenos descritos, y sus implicancias en materia de regulación y supervisión financiera, no tardaron en adquirir relevancia política. ${ }^{108} \mathrm{Si}$ las características definitorias de cada industria comenzaban a desaparecer y la naturaleza de las entidades que las desarrollaban tendía a confundirse, entonces los subsectores del mercado financiero y la naturaleza jurídica de sus participantes dejaban de operar como un criterio atendible de delimitación de ámbitos competenciales de los organismos encargados de su supervisión. Así, parece razonable migrar hacia otros esquemas de supervisión: para mantener una adecuada supervisión del mercado financiero, el diseño institucional del regulador debe ser capaz de reflejar adecuadamente — ser un espejo de - la industria que supervisa. ${ }^{109}$

Por todas estas razones, señala Elizabeth Brown, "en los últimos 15 años, los reguladores financieros y académicos han comenzado a formar un consenso acerca de que las aproximaciones institucionales o funciona-

${ }^{106}$ La difuminación de los límites entre sectores ya era constatada por la literatura a mediados de los años noventa. Véase, por ejemplo, C. Borio y R. Filosa, "The Changing Borders of Banking: Trends and Implications", BIS Working Papers 23 (1994); Taylor, “"Twin Peaks': A Regulatory Structure”; Goodhart, "Some Regulatory Concerns"; Briault, "The Rationale", 12.

107 Schooner y Taylor, "United Kingdom”, 320-322.

108 Véase, a modo de ejemplo, el proceso de consolidación regulatoria iniciado en el Reino Unido, Alemania (ambos hacia modelos integrados) y Australia (hacia twin peaks) a fines de los años noventa. Los argumentos utilizados en el Reino Unido para la unificación de todos los supervisores financieros en un organismo único son preclaros al respecto. Así arguyó ante la Cámara de los Comunes, en mayo de 1997, Gordon Brown, entonces Canciller de Hacienda: "En años recientes, se han difuminado las diferencias entre los distintos negocios de servicios financieros: bancos, sociedades de préstamo inmobiliario, empresas de inversión, compañías de seguro y otros. Esto ha aumentado la complejidad de la regulación financiera. El gobierno cree que el actual sistema es costoso, ineficiente y confuso tanto para las firmas reguladas como para sus clientes" (citado en Briault, "The Rationale", 6).

109 Taylor y Abrams, "Issues"; Briault, "The Rationale", 5 y 14; M. Taylor, "Peak Practice: How to Reform the UK's Regulatory System", Centre for the Study of Financial Innovation, 1996; Goodhart et al., Financial Regulation. 
les para regular los servicios financieros ya no funcionan y las estructuras regulatorias necesitan ser organizadas para abordar objetivos o riesgos". ${ }^{110}$

Además, los modelos de múltiples agencias implican necesariamente lidiar con problemas derivados de su propia estructura: (i) pobre coordinación entre ellas; (ii) contiendas de competencia; (iii) riesgos de arbitraje regulatorio; (iv) regulaciones inconsistentes; (v) comportamientos de mutua inhibición por deferencia; (vi) duplicación de esfuerzos, y (vii) difuminación de responsabilidades. ${ }^{111}$

A modo de conclusión de este apartado, es posible señalar que el sistema tradicional de supervisión nacional posiblemente se encuentra basado en silos o industrias, en virtud de razones históricas que ya no existen y que lo vuelven insostenible hacia el futuro. Brown, de nuevo: "Durante el siglo XIX y la primera parte del XX, los mercados de bancos, valores y seguros, así como las firmas que comercializaban dichos bienes y servicios se encontraban separados unos de otros y tenían un alcance local o regional más que nacional o internacional. Hoy en día, sin embargo, los mercados de servicios financieros ya no funcionan de ese modo". ${ }^{112}$ Constatándose la obsolescencia de nuestro modelo actual, surge de inmediato la pregunta acerca del sistema al que debiésemos migrar.

\section{LA PROMESA DE LA LEY 21.000: DESDE UN MODELO DE SILOS A UN ESQUEMA SEMI INTEGRADO113}

En el presente apartado intentaremos explicar por qué la dictación de la Ley 21.000 supone el puntapié inicial de una reestructuración completa en nuestra arquitectura de la supervisión y la relevancia que ello tiene para el adecuado funcionamiento del sistema financiero.

110 E. Brown, "Prior Proposals to Consolidate Federal Financial Regulators", The Volcker Alliance. Working for Effective Government, 2015, 9 (traducción libre). En el mismo sentido, ver Goodhart, "Some Regulatory Concerns", 614.

${ }^{111}$ Brown, "E Pluribus", 27.

112 Ibídem, 4.

113 Utilizamos el concepto de semi integrado intentando denotar que el Banco Central de Chile no sufrirá modificaciones en sus facultades de supervisión macroprudencial. Al mismo tiempo, el Servicio Nacional del Consumidor mantendrá sus atribuciones en materia de protección del consumidor y la Superintendencia de Pensiones, en la fiscalización de las administradoras de fondos previsionales. En un modelo integrado puro, la totalidad de las funciones relacionadas con el mercado financiero se consolidan en un solo órgano. 


\subsection{Breve explicación sobre su tramitación legislativa}

El 3 de julio de 2013 — primer mandato del Presidente Sebastián Piñera-, el ejecutivo ingresó el proyecto de ley que creaba la Comisión de Valores y Seguros (CVS). ${ }^{114}$ La iniciativa tenía como objetivo principal — si bien no exclusivo- ${ }^{115}$ modernizar el gobierno corporativo de la Superintendencia de Valores y Seguros (SVS), pasando desde un modelo unipersonal a uno colegiado, ${ }^{116}$ con el objetivo de alcanzar los beneficios que tales formas de gobernanza prometen; a saber: mayores niveles de independencia del poder central, ${ }^{117}$ consistencia dinámica, racionalización de las decisiones, mayores exigencias de fundamentación, aprovechamiento de las diversas experiencias profesionales y académicas de sus miembros, entre otros.

Luego, en noviembre de 2014 y durante el segundo mandato de la Presidenta Michelle Bachelet, se convocó a un grupo de expertos para formar un equipo técnico de trabajo - presidido por el profesor de derecho administrativo Luis Cordero, grupo que designaremos como "Comisión Cordero"-, con el objetivo de analizar el proyecto y determinar qué aspectos de éste era necesario reforzar o modificar. ${ }^{118}$

Por otro lado, y hacia fines de abril del año 2015, el Consejo Asesor Presidencial contra los Conflictos de Interés, el Tráfico de Influencias y la Corrupción, que abreviaremos como "Comisión Engel", presentó relevantes sugerencias sobre el gobierno corporativo de los supervisores sectoriales, con la finalidad de ofrecer mayores niveles de confianza, credibilidad y transparencia en los mercados. ${ }^{119}$

114 Véase Boletín 9015-05: https://www.camara.cl/pley/pley_detalle. aspx?prmID=9420/.

115 Otros objetivos del proyecto de ley en comento consistían en favorecer la legitimidad y debido proceso en la aplicación de sanciones y mayores exigencias de transparencia y accountability.

116 Véase Mensaje 011-361: https://www.camara.cl/pley/pley_detalle. aspx?prmID=9420/.

${ }^{117}$ Véase Pardow, “¿Control o autonomía?: El debate sobre agencias regulatorias independientes", inédito.

118 Véase Mensaje 532-363, de 12 de junio de 2015: https://www.camara.cl/ pley/pley_detalle.aspx?prmID=9420/.

119 Véase Informe final del Consejo Asesor Presidencial contra los conflictos de interés, el tráfico de influencias y la corrupción, 84 y ss, http://consejoanticorrupcion.cl/informe/. 
Recibidos los informes de la Comisión Cordero ${ }^{120}$ y de la Comisión Engel, se presentó, el 12 de junio de 2015, ${ }^{121}$ una indicación al proyecto que crea la CVS, con el objetivo de incorporar modificaciones que siguen de cerca sus recomendaciones. Así, se introdujeron relevantes cambios para el fortalecimiento de la CVS: (i) ampliación de su mandato institucional, incluyendo el deber de promover el desarrollo del mercado; (ii) reforzamiento de sus facultades de fiscalización, detección y sanción (por ejemplo, medidas intrusivas, levantamiento de secreto bancario y perfeccionamiento del mecanismo de delación compensada); (iii) extensión de la protección legal a todos sus funcionarios; ${ }^{122}$ (iv) establecimiento del requisito de dedicación exclusiva para los comisionados; ${ }^{123}$ (v) fortalecimiento del régimen de postempleo; (vi) incorporación de mecanismos de coordinación regulatoria, y (vii) creación de un Comité de Autorregulación, entre otros.

Luego, en noviembre de 2015, el ejecutivo presentó una indicación sustitutiva que introduce algunos aportes y mejoras recogidos del trabajo legislativo que se desarrolló principalmente en la Comisión de Hacienda del Senado. Ahora bien, este ejercicio pareciera haber tenido por objetivo principal facilitar y hacer operativa la tramitación legislativa, más que introducir cambios sustantivos respecto de la indicación ya formulada en junio. ${ }^{124}$

A fines de 2016, motivado principalmente por acontecimientos de alta connotación pública acaecidos en el mercado financiero nacional y que dejaron al descubierto una serie de deficiencias en materia de supervisión financiera, el ejecutivo decidió promover un acuerdo parlamentario transversal para que la cámara de origen rechazare los cambios propuestos por la cámara revisora, con la idea de forzar una comisión mixta y generar una oportunidad de presentar adecuaciones de gran envergadura al proyecto que se venía tramitando desde 2013.

${ }^{120}$ Cordero et al., Informe final. Grupo de trabajo para el fortalecimiento institucional del mercado de capitales (Santiago, 2015).

${ }^{121}$ Véase el ya citado Mensaje 532-363.

122 En el proyecto de ley original, la defensa legal se limitaba únicamente a comisionados y al fiscal de la CVS.

${ }^{123}$ En el proyecto original, únicamente el presidente de la Comisión tendría dedicación exclusiva.

${ }^{124}$ Véase Mensaje 1272-363, de 11 de noviembre de 2015: https://www.camara.cl/pley/pley_detalle.aspx?prmID=9420. 
Alcanzándose dicho acuerdo, la Presidenta de la República presentó al Senado, el 26 de octubre de 2016, una propuesta para resolver las divergencias surgidas entre ambas cámaras. ${ }^{125}$ En dicha instancia, la reforma más relevante consistió en sustituir a la CVS por una nueva Comisión para el Mercado Financiero (CMF) —en los términos que serán explicados luego-. Esta última formulación del proyecto de ley fue aprobada en la Comisión Mixta y ratificada en votación prácticamente unánime en el pleno del Congreso Nacional. Así las cosas, la Ley 21.000 fue finalmente publicada el 23 de febrero de 2017.

\subsection{La promesa}

La creación de la CMF introduce, desde ya, algunas mejoras relevantes en el fortalecimiento institucional de la ex SVS, pero no implica un cambio radical en nuestro esquema de supervisión, limitándose a formular una promesa de que dicho cambio se materializará en el futuro. En virtud de la confusión que podría generar esta fórmula, conviene detenerse a explicar las implicancias que tiene la aprobación de la Ley 21.000 para la arquitectura de la supervisión nacional.

La relevancia fundamental del giro que sufrió el proyecto de ley en comento en la comisión mixta se explica en virtud de que la Ley 21.000 introduce una notable ampliación de la misión institucional del nuevo organismo - la CMF-, en los términos establecidos en el inciso segundo del artículo 1 del DL 3.538 modificado por el artículo primero de la Ley 21.000 (los énfasis son míos):

Corresponderá a la Comisión, en el ejercicio de sus potestades, velar por el correcto funcionamiento, desarrollo y estabilidad $\mathrm{del}$ mercado financiero, facilitando la participación de los agentes de mercado y promoviendo el cuidado de la fe pública. Para ello deberá mantener una visión general y sistémica del mercado, considerando los intereses de los inversionistas y asegurados.

Las implicancias que traería aparejadas este cambio de formulación de la misión institucional del nuevo organismo son enormes. La referencia al mercado financiero en su completitud y el mandato de

${ }^{125}$ Mensaje 208-364, de 26 de octubre de 2016, https://www.camara.cl/pley/ pley_detalle.aspx?prmID $=9420$. 
desempeñar sus funciones manteniendo una visión holística del sistema financiero significarían, en principio, el paso desde un organismo que únicamente supervisaría los mercados de valores y seguros - la propuesta CVS del proyecto original - a otro que tendrá a su cargo la supervigilancia del mercado financiero en su totalidad — la CMF-; ello, con la única excepción de las administradoras de fondos de pensiones por expresa disposición legal. ${ }^{126}$

Lo anterior, implicaría, en principio, que la CMF debiese absorber al menos ${ }^{127}$ las funciones que hasta la fecha le correspondieron tanto a la SVS como a la Superintendencia de Bancos e Instituciones Financieras (SBIF).

Ahora bien, introducir un cambio de esta envergadura en tercer trámite constitucional y en el seno de una comisión mixta podría haber acarreado serios problemas político-institucionales. ${ }^{128}$ Así las cosas,

${ }^{126}$ Véase el artículo 3 del Decreto Ley 3538 modificado por el artículo primero de la Ley 21.000 .

127 En nuestro entendimiento, la forma de atribución de competencias utilizada haría, en principio, irrelevantes las naturalezas jurídicas de los sujetos fiscalizados y, por tanto, quedarían obsoletas las formas de determinación del perímetro regulatorio empleadas anteriormente. Con ello, dejaría de existir la distinción entre entidades fiscalizadas y no fiscalizadas, en la medida en que desarrollen actividades en el mercado financiero. En virtud de lo anterior, bien podrían quedar dentro del perímetro regulatorio de la CMF entidades que en la actualidad no son fiscalizadas ni por la SVS ni por la SBIF, aunque, como veremos, dicha conclusión resulta apresurada - al menos, por ahora-. Sobre las implicancias que podría tener la dictación de la Ley 21.000 en la determinación del perímetro regulatorio de la Comisión para el Mercado Financiero, véase Lambeth y Morales, "La Comisión".

128 Entre otras, las modificaciones introducidas podrían: (i) haber dado pie para controvertir la posibilidad de incluir tal cambio dentro de las ideas matrices del proyecto original y, con ello, generar vicios formales que imposibilitaran la viabilidad del proyecto; (ii) haber generado complejas consecuencias en la relación entre el ejecutivo y las asociaciones de funcionarios afectadas por el cambio de último minuto; (iii) resultar demasiado abruptas y poco preparadas (existen buenas razones de diseño institucional para privilegiar mecanismos de consolidación gradual por sobre aquéllos denominados del tipo big-bang, por lo que resultaba razonable ampliar el período de adaptación), y (iv) ser criticadas por una falsación del proceso de deliberación democrática. Así, la alternativa empleada por el ejecutivo fuerza una discusión parlamentaria completa sobre el modelo de supervisión financiera que se adoptará en Chile, la que se encuentra teniendo lugar en el contexto de la tramitación del Proyecto de Ley que Moderniza la Legislación Bancaria. Todo lo anterior hace relativamente razonable la fórmula utilizada por el ejecutivo de prometer — pero no materializar - el paso a un modelo semi integrado. 
el legislador optó por limitarse a formular una promesa, sin introducir cambios inmediatos en el esquema de supervisión financiera. De este modo, la aparente amplitud de giro que implica la nueva formulación de la misión institucional de la CMF contenida en el artículo 1 del DL 3.538 modificado por el artículo primero de la Ley 21.000, anteriormente transcrito, fue inmediatamente limitada en sus consecuencias prácticas por el artículo 3 del mismo DL 3.538 modificado. En esta última disposición se mantuvo un listado de entidades fiscalizadas que no amplía las competencias que le corresponderá ejercer a la CMF, respecto de las entidades que ya supervigilaba la SVS. De este modo, se mantuvo la lógica de silos existente antes de la aprobación de la Ley 21.000. Por lo tanto, la CMF se encuentra operando como continuadora legal de la SVS, sin absorber ninguna de las funciones del otro supervisor financiero: la SBIF.

Resulta explícito, en tal sentido, el artículo tercero transitorio de la Ley 21.000. Dicha disposición tuvo por objetivo aclarar que, pese a la amplitud del mandato contenido en el artículo 1 del DL 3.538 modificado, la CMF no ejercería de inmediato sus potestades respecto de las entidades supervigiladas por la SBIF y ofrecer garantías de que la promesa del ejecutivo de integrar ambos reguladores sería cumplida (los énfasis son míos):

Artículo tercero transitorio: Sin perjuicio de lo dispuesto en los artículos 1 y 3 contenidos en el artículo primero de esta ley, la Comisión para el Mercado Financiero no podrá ejercer sus competencias respecto de las personas, entidades o actividades sujetas expresamente al control de la Superintendencia de Bancos e Instituciones Financieras, sino hasta que se materialice la modificación legal que la habilite para ejercer competencias respecto de dichas personas, entidades y actividades. En la modificación aludida deberán establecerse las formas y condiciones en que dichas facultades serán ejercidas.

En cumplimiento de lo anterior, el Presidente de la República deberá enviar al Congreso Nacional, dentro del plazo de un año desde la publicación de esta ley, un proyecto de ley que modifique el decreto con fuerza de ley $N^{o}$ 3, de 1997, del Ministerio de Hacienda, que fija el texto refundido, sistematizado y concordado de la Ley General de Bancos y de otros cuerpos legales que se indican. 
La promesa del ejecutivo de presentar un proyecto de ley que concretizare la propuesta de integración fue cumplida pocos meses después, cuando, el 13 de junio de 2017, la ex Presidenta Michelle Bachelet presentó el proyecto de ley que Moderniza la Legislación Bancaria. ${ }^{129}$

\subsection{Comparación entre las principales alternativas disponibles}

En las últimas décadas, los modelos integrados y de twin peaks se han posicionado como las alternativas con mayor capacidad para supervisar adecuadamente los mercados financieros actuales. Por la misma razón, fueron los esquemas explorados por el ejecutivo durante el proceso de elaboración de la propuesta de consolidación regulatoria. ${ }^{130}$ En ese contexto, resulta atendible confrontar ambos modelos con sus principales ventajas y problemas. Luego, explicaremos por qué parece razonable que en Chile se haya optado por un modelo semi integrado de supervisión financiera.

Los países que han optado por los modelos de supervisión integrada han esgrimido una serie de argumentos que justificarían su elección. ${ }^{131}$ Típicamente, se sostiene que se hacen cargo de mejor modo de la difuminación de los límites entre industrias, del surgimiento de conglomerados, así como del aumento en la complejidad ${ }^{132}$ e interconexión ${ }^{133}$ del sistema. Al mismo tiempo, permitirían respon-

${ }^{129}$ Véase el Boletín 11.269-05.

${ }^{130}$ Véase el "Informe de productividad" que acompañó la presentación del Proyecto de Ley que Moderniza la Legislación Bancaria.

${ }^{131}$ El presente apartado sistematiza los argumentos con que se ha defendido la adopción de modelos integrados. Ahora bien, los artículos citados, como referencias, incorporan encuestas o fundamentos ofrecidos por distintos países, expertos, académicos, miembros de las burocracias o políticos, que no necesariamente representan la opinión de los respectivos autores. En ese sentido, las referencias que se ofrecen servirán al lector para profundizar argumentos, pero no necesariamente reflejan la opinión del autor referenciado.

132 Her Majesty's Treasury, Financial Services and Markets Bill: A Consultation, 1998; Briault, "The Rationale", 12; C. Briault, "Revisiting the Rationale for a Single National Financial Services Regulator", UK, FSA Occasional Paper Series 16 (2002): 6-8; De Luna Martínez y Rose, "International Survey", 7; BaFin. Annual Report, Bundesanstalt für Finanzdienstleistungsaufsicht, 2002; Brown, "E Pluribus", 4-5; Brown, "Prior Proposals", 11.

${ }^{133}$ E. Brown, "The New Laws and Regulations for Financial Conglomerates: Will they Better Manage the Risks than the Previous Ones?", American University Law Review 60-5, n. ${ }^{\circ} 2$ (2011), 1341. 
der mejor ante el surgimiento de nuevas actividades e innovaciones financieras. ${ }^{134-135}$ Todo lo anterior, se explicaría en virtud de que un mismo organismo supervisará el mercado completo, sin necesidad de distribuir ámbitos competenciales utilizando criterios de delimitación cada vez menos operativos.

La presencia de conglomerados financieros y el surgimiento de nuevos instrumentos, que agregan o desagregan características propias de los vehículos financieros tradicionales, habrían vuelto imposible efectuar distinciones precisas entre entidades, actividades, tipos de objetivos o riesgos involucrados, todos los cuales, además, pueden hacer surgir problemas tanto desde una perspectiva prudencial como conductual, siendo complejo distinguir entre la una y la otra. ${ }^{136}$ Ello, según los defensores de este tipo de modelos, haría razonable la creación de organismos únicos con un mandato omnicomprensivo y un marcado componente prospectivo. ${ }^{137}$ Así las cosas, los modelos integrados serían un mejor reflejo de la forma en que se encuentran estructurados los mercados actuales. ${ }^{138}$

Por otra parte, se ha sostenido que los modelos integrados permiten actuar con rapidez y efectividad ante el surgimiento de riesgos para la estabilidad financiera, en tanto hacen posible ponderar objetivos con mayor flexibilidad, por lo que se evita que decisiones urgentes se traben por eventuales desacuerdos entre organismos. ${ }^{139}$

134 Taylor y Fleming, "Integrated Financial Supervision", 28.

135 La capacidad de respuesta que, por ahora, ofrecerá la Comisión para el Mercado Financiero respecto de nuevas actividades o innovaciones financieras no gozará de los beneficios que supondría una arquitectura integrada de supervisión. Ello, en razón de la forma en que se siguen determinando los ámbitos competenciales del regulador. Para un análisis pormenorizado de este problema, véase Lambeth y Morales, "La Comisión".

${ }^{136}$ Brown, "E Pluribus", 39-41 y 76-77.

${ }^{137}$ Sobre la necesidad de mantener un enfoque prospectivo y dinámico en las actividades de supervisión financiera, véase Mori, From Static Regulation, 122-141.

138 Briault, "Revisiting", 7.

139 Briault, "The Rationale", 21; y Briault, "Revisiting", 7. Algunos autores han sostenido que resulta más razonable que este tipo de ponderaciones sean resueltas a nivel político, con el consiguiente aumento en los grados de legitimación democrática que podrían derivarse de tales decisiones. Véase, por ejemplo, Taylor, “"Twin Peaks': A Regulatory Structure”, y Goodhart et al., Financial Regulation. 
La centralización de la supervisión del sistema en un único organismo facilita la supervisión basada en riesgos, ${ }^{140}$ y la evaluación de riesgos consolidados de la industria ${ }^{141}$ y de conglomerados, característica que se torna crucial cuando los propios conglomerados adoptan una aproximación centralizada de administración y adquisición de riesgos. ${ }^{142}$

Los modelos integrados, adicionalmente, evitarían la dilución de responsabilidades entre organismos diversos y, por tanto, fortalecerían el accountability del regulador financiero, ${ }^{143}$ el que deberá hacerse cargo de responder de los fallos relevantes del sistema cuando éstos hubieren debido preverse.

Los modelos de supervisión en comento, a su vez, minimizan los riesgos de arbitrajes regulatorios, aplicando una aproximación consistente a los distintos segmentos del mercado y evitando que los regulados estén en condiciones de elegir una normativa menos rigurosa o un supervisor más blando. ${ }^{144-145}$ Los arbitrajes regulatorios pueden ser especialmente perniciosos cuando gatillan una competencia en laxitud o permisividad entre supervisores, lo que no ocurriría - al menos a nivel nacional ${ }^{146}$ en los modelos que cuentan con un supervisor integrado. ${ }^{147}$

Con un argumento relacionado, se ha sostenido que los modelos de supervisión integrados permiten mayores grados de armonía, racionali-

${ }^{140}$ Briault, "Revisiting”, 25; Brown, "Consolidated Financial Regulation”, 24.

141 De Luna Martínez y Rose, "International Survey", 2; Goodhart et al., Financial Regulation, 148; Brown, "Consolidated Financial Regulation", 58; K. Mwenda, "Legal Aspects of Unified Financial Services Supervision in Germany", German Law Journal 4 (2003); Brown, "E Pluribus", 1 y 9.

${ }^{142}$ Llewellyn, "Institutional Structure", 18.

143 De Luna Martínez y Rose, "International Survey", 7-8; Briault, "The Rationale", 22; Briault, "Revisiting”, 7; Taylor, "Twin Peaks': A Regulatory Structure"; Goodhart et al. Financial Regulation; Brown, "Consolidated Financial Regulation", 68; Llewellyn, "Institutional Structure", 19-21 y 24-25; Brown, "E Pluribus", 76-76.

${ }^{144}$ De Luna Martínez y Rose, "International Survey", 2, 5 y 7-8.

145 Taylor y Abrams, "Issues".

${ }^{146}$ En un mercado globalizado, la competencia regulatoria puede darse perfectamente a nivel internacional. Según algunos expertos, esto habría ocurrido entre Nueva York y Londres en el período previo a la crisis de 2008. Véase, por ejemplo, Brown, "A Comparison", 528; y Brown, "Consolidated", 85-86.

147 Brown, "Prior Proposals", 30-31; Brown, "E Pluribus", 82; Llewellyn, "Institutional Structure", 20. 
dad y consolidación regulatoria, ${ }^{148}$ mientras que aseguran la neutralidad competitiva entre los distintos sectores ${ }^{149} \mathrm{y}$ evitan riesgos de regulación excesiva por duplicidades. ${ }^{150} \mathrm{La}$ sistematicidad regulatoria y el hecho de que la competencia se desarrolle en una cancha nivelada debiesen impactar positivamente en los niveles de eficiencia observables en el mercado.

Se sostiene también que los modelos integrados tienden a reducir los riesgos de captura regulatoria, en tanto los intereses de distintos sectores de la industria son discordantes y compiten entre sí, por lo que resultaría menos probable que un determinado actor o industria logre capturar al regulador. En caso de que ello ocurriese, la vulneración de la neutralidad competitiva despertaría de inmediato las críticas y quejas de parte de los sectores perjudicados. ${ }^{151}$

En materia de eficiencias, se señala que los modelos integrados reducen la duplicidad de esfuerzos entre organismos ${ }^{152}$ por la vía de minimizar las superposiciones de competencias, ${ }^{153}$ evitan los riesgos de vacíos regulatorios y puntos ciegos de supervisión, ${ }^{154} \mathrm{y}$, a la vez, eliminan relevantes costos de transacción asociados a la coordinación entre múltiples organismos. ${ }^{155-156}$

Además, permiten alcanzar ciertas economías de escala y de ámbito, tanto en las actividades esenciales del supervisor como en labores anexas

148 De Luna Martínez y Rose, "International Survey", 5 y 17; Briault, "Revisiting", 19; Brown, "Consolidated Financial Regulation", 24; Llewellyn, "Institutional Structure", 24; Briault, "The Rationale"; Brown, "E Pluribus", 75.

149 Llewellyn, "Institutional Structure", 19-20; Brown, "E Pluribus", 11; Brown, "Consolidated Financial Regulation", 24.

${ }^{150}$ Brown, "E Pluribus", 75.

${ }^{151}$ J. Macey, "Organizational Design and Political Control of Administrative Agencies", Journal of Law, Economics y Organization 8, n. ${ }^{\circ}$ (1992); Pardow, “¿Control o autonomía?”; Brown, "E Pluribus”, 50 y 79.

${ }^{152}$ Llewellyn, "Institutional Structure", 19; De Luna Martínez y Rose, "International Survey", 7-8.

${ }^{153}$ Llewellyn, "Institutional Structure", 19; Brown, "E Pluribus", 33.

${ }^{154}$ Llewellyn, "Institutional Structure”, 19; De Luna Martínez y Rose, "International Survey", 11.

${ }^{155}$ Briault, "The Rationale", 18; De Luna Martínez y Rose, "International Survey", 7-8; Llewellyn, "Institutional Structure", 19; Brown, "E Pluribus", 36.

${ }^{156}$ Un regulador único de todos modos puede exhibir problemas de comunicación, intercambio de información, coordinación y consistencia. Véase, por ejemplo, Goodhart et al. Financial Regulation. 
al giro principal. En ese sentido, se lograrían eficiencias en el desarrollo de actividades de regulación, fiscalización y sanción; en el establecimiento de una forma de administración común; en una aproximación única a la fijación de estándares; en procedimientos comunes de autorización, supervisión y fiscalización, así como de revisión de la información aportada por los fiscalizados. ${ }^{157}$ En materias anexas al giro principal, con un único regulador se alcanzarían eficiencias en la utilización de los recursos públicos, ${ }^{158-159}$ evitando duplicar departamentos de recursos humanos, divisiones de información, seguridad y tecnología, de control financiero, recopilación y tratamiento de datos, a la vez que permitiría ahorros en infraestructura, equipamientos, softwares, entre otros. ${ }^{160}$

Como argumentos adicionales, se ha sostenido que son modelos más simples, por lo que pueden ser fácilmente comprendidos por consumidores y sujetos fiscalizados; ${ }^{161}$ que ofrecen más confianza, transparencia y credibilidad al interior de los mercados financieros; ${ }^{162}$ al tiempo que permiten mayores espacios para innovación financiera ${ }^{163}$ y regulatoria. ${ }^{164}$ Además, ofrecen un punto de contacto común para consumidores, entidades reguladas ${ }^{165}$ y para reguladores extranjeros o internacionales. ${ }^{166}$

Los sistemas integrados también generan economías para los agentes de mercado, quienes deberán entregar información a una única entidad y mantener una contraparte específica para sus procesos de

${ }^{157}$ De Luna Martínez y Rose, "International Survey”, 8; Briault, "Revisiting”, 7 y 16; Llewellyn, "Institutional Structure", 19.

158 Briault, "The Rationale", 6-7; De Luna Martínez y Rose, "International Survey", 6 y 8; Briault, "Revisiting", 7.

${ }^{159}$ Los argumentos sobre economías de escalas para pasar hacia modelos de supervisión integrada han sido particularmente poderosos en economías pequeñas. Véase, por ejemplo, De Luna Martínez y Rose, "International Survey”, 11; Llewellyn, "Institutional Structure", 19; Taylor y Fleming, "Integrated Financial Supervision". Sobre este punto volveremos con mayor detención luego.

${ }^{160}$ Briault, "The Rationale", 18.

${ }^{161}$ Llewellyn, "Institutional Structure", 20; Office of the Comptroller of the Currency. US Department of the Treasury, National Banks and the Future (U.S. Government Printing Office, 1962), citado en Brown, "Prior Proposals", 44.

162 Brown, "Consolidated Financial Regulation", 58.

163 Brown, "E Pluribus", 83.

164 Ibídem, 76 y 83.

165 Briault, "The Rationale", 18.

166 Brown, "E Pluribus", 79. 
cumplimiento. ${ }^{167}$ Los costos de compliance en industrias o sectores sofisticados de la economía pueden llegar a ser elevados, por lo que una reducción de los gastos en esta materia podría - en un escenario en que los agentes económicos disipen rentas en el proceso competitivo- llegar a impactar el valor de los servicios financieros. Por otra parte, los reguladores integrados estarían en una mejor posición para administrar eficientemente los recursos que se destinarán a fiscalización entre las distintas actividades y sujetos supervisados. ${ }^{168}$

Otro argumento ofrecido es que un supervisor integrado es capaz de contrapesar mejor a los grandes conglomerados financieros. Lo anterior, puede hacer recomendable la adopción de tales modelos en países en que existen altos niveles de concentración en la industria. ${ }^{169}$

Además, un regulador integrado, según los expertos, resultaría más atractivo para ejecutivos y profesionales destacados, lo que permitiría retener capital humano sofisticado por períodos más extensos. ${ }^{170}$ Este argumento puede ser especialmente relevante cuando este capital es escaso en un determinado país. ${ }^{171}$

Los modelos integrados, por otra parte, ofrecen un mayor nivel de flexibilidad en su organización interna debido a que no requieren reformar otros organismos ni la dictación de normas de carácter legal para introducir relevantes reestructuraciones. ${ }^{172}$ De tal manera, un supervisor integrado podrá, por ejemplo, decidir mantener silos en su estructura interna — como el BaFin alemán - o generar una estructura interna que responda a determinados objetivos — por ejemplo, prudenciales y conductuales- Ésta podría ser una característica crucial: en la medida en que ningún sistema es perfecto ni extrapolable a cualquier realidad, tener la posibilidad de ensayar distintas alternativas y de adaptarse internamente a lo largo del tiempo puede revestir una utilidad decisiva a la hora de optar por un determinado esquema institucional.

167 De Luna Martínez y Rose, "International Survey”, 8; Llewellyn, "Institutional Structure", 21.

168 Briault, "The Rationale", 20.

169 Véase, por ejemplo, Taylor y Fleming, "Integrated Financial Supervision”.

170 De Luna Martínez y Rose, "International Survey”, 8; Llewellyn, "Institutional Structure", 19.

${ }^{171}$ Briault, "The Rationale”, 21; Taylor, “Twin Peaks': A Regulatory Structure".

172 Taylor y Fleming, "Integrated Financial Supervision”, 17 y Taylor, “"Twin Peaks' Revisited”, 12-13. 
Ahora bien, también se han ofrecido relevantes críticas a los esquemas de supervisión integrados. Los principales argumentos que se han esgrimido en contra de dichos esquemas suelen provenir de distintos lugares: aversión a la consolidación y complejidades prácticas de llevarla a cabo; excesiva concentración de poder en un único organismo, y problemas derivados del mandato de velar por objetivos eventualmente incompatibles (por ejemplo, prudenciales y conductuales). En relación con este último punto, suele señalarse que los modelos de twin peaks corren con ventaja.

En general, los opositores a la consolidación de funciones argumentan que el sistema fragmentado no requiere de mayores intervenciones; que la diversidad de reguladores favorece la competencia regulatoria y conduce a una mejor regulación — porque el arbitraje regulatorio evitará la sobrerregulación - ; que la reforma creará incertidumbre innecesaria, lo que impactará negativamente en el funcionamiento del mercado, ${ }^{173}$ y que se generarán ineficiencias y pérdidas de efectividad en la transición. ${ }^{174}$

Numerosos autores sostienen, además, que las pretendidas ventajas de los modelos integrados no son demasiado relevantes. En ese sentido, argumentan que los problemas de coordinación en los modelos de agencias múltiples no son considerables y pueden ser solucionados mediante fórmulas menos disruptivas que la consolidación de funciones. ${ }^{175} \mathrm{Al}$ mismo tiempo, sostienen que la armonía regulatoria no es un fin en sí mismo y que se tenderá a adoptar soluciones del tipo one-size-fits-all, las que no se hacen cargo adecuadamente de las características de cada sector. ${ }^{176}$ Finalmente, arguyen que las pretendidas economías de escala y ámbito no son significativas. ${ }^{177}$

${ }^{173}$ Brown, "Consolidated Financial Regulation", 11.

${ }^{174}$ De Luna Martínez y Rose, "International Survey”, 5; C. Goodhart, "The Organisational Structure of Banking Supervision", Economic Notes 31, n. ${ }^{\circ}$ (2002).

175 De Luna Martínez y Rose, "International Survey”, 2, citando a Goodhart, "The Organisational Structure"; B. Downe, "The Canadian Banking Model and Lessons Learned from the Global Financial Crisis", 2010.

176 Goodhart, "The Organisational Structure"; De Luna Martínez y Rose, "International Survey", 5 y 8; Llewellyn, "Institutional Structure", 22 y 26. En este punto, se ha llamado la atención sobre la necesidad de que la regulación financiera varíe de acuerdo al tamaño, alcance y actividades que desarrolle cada tipo de agente financiero. Lo anterior, permitirá generar un sistema de regulación más efectivo y eficiente. Véase Tarullo, "Rethinking", 1-4.

${ }^{177}$ De Luna Martínez y Rose, "International Survey", 5 y 9; Llewellyn, "Institutional Structure", 22-23. 
Por otra parte, indican que los modelos integrados provocarán consecuencias negativas. Primero, en tanto tenderán a la sobrerregulación del mercado financiero, por la vía de eliminar la competencia entre los organismos competentes. ${ }^{178-179}$ Segundo, en razón de que, al no contar con un esquema claro de frenos y contrapesos, se transformarán en organismos demasiado grandes, pesados, burocrático, lentos ${ }^{180}$ y arbitrarios. ${ }^{181}$ Tercero, porque pueden hacer surgir riesgo moral en la industria, ante la percepción pública de que el espacio de riesgo de las instituciones financieras ha desaparecido por la existencia de un regulador fuerte y de un tratamiento pretendidamente equivalente de todos los instrumentos financieros, con la consiguiente aplicabilidad de garantías estatales y otros mecanismos que conformen la red de seguridad del sistema. ${ }^{182}$

Como argumentos adicionales, se indica que los modelos integrados sólo funcionarían en algunos países con mercados financieros desarrollados; ${ }^{183}$ que existe riesgo de que se produzca el efecto árbol de navidad ${ }^{184-185}$ o de abrir una caja de Pandora con consecuencias un tanto inesperadas en el proceso legislativo (negociaciones, grupos de

178 Brown, "Consolidated Financial Regulation", 24 y 69; Brown, "Prior Proposals", 53; Brown, "E Pluribus", 9; Llewellyn, "Institutional Structure", 22.

${ }^{179}$ La sobrerregulación se produciría en virtud de que los consumidores no tienen un límite de disposición a pagar por la regulación: mientras que ésta evidentemente tiene un costo para el sistema financiero, no tiene un precio que los consumidores deban pagar directamente. En ese contexto, un regulador averso al riesgo estará dispuesto a sobreofertar regulación, mientras que el consumidor tenderá a sobredemandarla. Según algunos, este efecto sería contrarrestado en la medida en que los agentes de mercado arbitren regulatoriamente entre dos o más supervisores, lo que dejaría sin supervisados a aquella agencia que impone exigencias más gravosas de lo razonable. Para una explicación detallada del argumento, Llewellyn, "Institutional Structure", 5.

${ }^{180}$ De Luna Martínez y Rose, "International Survey", 2 y 8; Goodhart, "The Organisational Structure”; Taylor, “Twin Peaks”: A Regulatory Structure”; S. Wallis, Financial System Inquiry Final Report (Wallis Inquiry), Australian Government, 1997, 545-546; Llewellyn, "Institutional Structure", 25.

181 Véase, por ejemplo, la opinión de Alan Greenspan, presidente de la Reserva Federal de Estados Unidos entre 1987 y 2006, citada en: Brown, "Prior Proposals", 124.

182 Goodhart et al. Financial Regulation; Taylor y Abrams, "Issues".

183 De Luna Martínez y Rose, "International Survey", 5.

184 Taylor y Fleming, "Integrated Financial Supervision".

${ }^{185}$ Se denomina "Christmas tree effect" cuando a un organismo se le atribuye, de modo más o menos inestable, un amplio rango de funciones misceláneas, que lo sobrecargan y alejan de sus funciones y objetivos primarios. 
interés, captura, pérdida de personal relevante, pérdida del foco en las actividades de las agencias independientes, entre otras). ${ }^{186}$

Ahora bien, el principal argumento utilizado en contra de los modelos integrados y que inclinaría la balanza en favor de los modelos de twin peaks tiene que ver con la imposibilidad de los primeros de velar adecuadamente por objetivos prudenciales y conductuales. Suele citarse a modo ilustrativo un pasaje bíblico: "Nadie puede servir a dos señores, pues menospreciará a uno y amará al otro, o querrá mucho a uno y despreciará al otro". ${ }^{187}$

De este modo, las agencias con múltiples objetivos tendrían dificultades para priorizar unos sobre otros o balancearlos adecuadamente en caso de que entren en conflicto. ${ }^{188}$ A su vez, la solución que adopte el regulador integrado — en caso de colisionar ambos objetivos — será opaca y no estará expuesta a exigencias de responsabilidad y rendición de cuentas. ${ }^{189-190}$ Además, se esgrime que la cultura organizacional de un organismo con foco prudencial es distinta y muchas veces irreconciliable con una proveniente del mundo conductual, lo que podría generar numerosos conflictos al interior del organismo correspondiente. ${ }^{191}$

Finalmente, suelen predecir que, en hipótesis en que los objetivos de protección de consumidores e inversionistas entren en conflicto con los objetivos de carácter prudencial, ${ }^{192}$ las preocupaciones conductuales quedarán relegadas y los organismos encargados del enforcement tenderán a ser más suaves en sus actividades de fiscalización. ${ }^{193}$ En la otra cara de la misma moneda, algunos han sostenido que los reguladores

186 Taylor y Fleming, "Integrated Financial Supervision".

187 Mateo 6:24-34.

188 J. Chant, "Keeping the Genie in the Bottle: Grading the Regulation of Canadian Financial Institutions", SPP Research Paper No. 7-8, 2014; Brown, "Consolidated Financial Regulation", 37; Llewellyn, "Institutional Structure", 26; de Luna Martínez y Rose, "International Survey”, 29.

189 Ello no ocurriría, en opinión de Taylor, en caso de que la decisión sea tomada a nivel político. Taylor, “'Twin peaks': A Regulatory Structure”.

190 J. Chant, "Keeping the Genie"; Brown, "Consolidated Financial Regulation", 37; G. Thompson, "Regulatory Policy Issues in Australia", Reserve Bank of Australia, 1996.

${ }^{191}$ Llewellyn, "Institutional Structure", 26; Taylor y Abrams, "Issues".

192 "A Survey of Global Equity Markets: Regulators' Arbitrage", The Economist, 3 de mayo de 2001; Brown, "Consolidated Financial Regulation", 41.

${ }^{193}$ Brown, "Consolidated Financial Regulation”, 69; Llewellyn, "Institutional Structure", 25. 
integrados tenderán a privilegiar la persecución de objetivos conductuales y descuidarán su misión de carácter prudencial. Ello, en virtud de que los objetivos de naturaleza conductual ofrecen resultados medibles y notorios - mientras que los prudenciales suelen ser difíciles de conmensurar - y, además, los problemas de naturaleza conductual suelen ser políticamente sensibles y suscitar especial interés del público. ${ }^{194}$

Ahora bien, los modelos de cumbres gemelas también presentan relevantes dificultades. En los hechos, la distinción entre lo prudencial y lo conductual no es tan simple como el modelo de twin peaks pretende. ${ }^{195}$ De hecho, tal distinción es difícil de operativizar como mecanismo de atribución de competencias. ${ }^{196}$ Además, la difuminación de límites entre distintos sectores y la presencia de conglomerados financieros podría implicar que ciertas entidades estén sometidas de modo permanente a una doble supervisión, con las consiguientes ineficiencias tanto por duplicidad de esfuerzos de los reguladores como de los fiscalizados. ${ }^{197}$

Algunos de los problemas más relevantes de los modelos de twin peaks es que generan dificultades de coordinación entre las agencias encargadas de la supervisión, las que suelen comportarse de modo poco colaborativo y exhiben bajos niveles de comunicación entre ellas, ${ }^{198}$ lo que resulta complejo cuando necesariamente mantendrán espacios regulatorios compartidos. Dichos problemas han generado traslapes, descoordinaciones o falta de armonía, por ejemplo, en Australia (2001) y Holanda (2008-2009). ${ }^{199}$

\subsection{Circunstancias especiales del caso chileno que explicarían la elección de un modelo semi integrado}

Las razones que fueron tenidas a la vista para optar por un modelo semi integrado de supervisión para Chile —en desmedro de la alternativa de migrar a un esquema de twin peaks - obedecen, en nuestra

194 Taylor, "The Road", 81-82.

195 Briault, "The Rationale", 24-25.

${ }^{196}$ Llewellyn, "Institutional Structure", 24-25.

197 Briault, "The Rationale", 24-25.

198 Ibídem; Brown, "E Pluribus", 74.

199 "Informe de productividad. Proyecto de Ley que Moderniza la legislación bancaria, adecuando normativa que indica". Mensaje 63-365. Ministerio de Hacienda, 13 de junio de 2017, 19. 
opinión, a tres tipos de argumentos. El primero se presenta en un nivel teórico y tiene relación con la forma en que se relacionan preocupaciones prudenciales y conductuales. El segundo se refiere a características estructurales del mercado chileno de capitales. Y el tercero se relaciona con cuestiones puramente contingentes ocurridas durante la tramitación del proyecto de ley.

En primer lugar, es posible constatar que las preocupaciones conductuales y prudenciales no necesariamente son antagónicas —o no lo son con la intensidad en que pretenden los promotores de los esquemas de twin peaks-. De hecho, ambos objetivos se encuentran alineados en el largo plazo y son interdependientes. ${ }^{200}$ Resulta imposible satisfacer adecuadamente un mandato prudencial sin mantener una relevante preocupación conductual, y viceversa. En ese contexto, las hipótesis en que se presentarán conflictos concretos donde habrá que privilegiar un mandato sobre otro son excepcionales y se manifestarán de forma esporádica. Tales eventos - por cuanto excepcionales - no necesariamente justifican la decisión de separar orgánicamente dichas labores en dos organismos independientes. Ello, sobre todo en un país en que el capital humano necesario para cubrir ambas labores es escaso.

En ese sentido, no resulta recomendable sobredimensionar la magnitud de la irreconciliabilidad de los objetivos prudenciales y conductuales. Las crisis financieras iniciadas por problemas de carácter conductual tienen una probabilidad baja de ocurrencia y, en razón de su gravedad, de acaecer, deberá tenderse a privilegiar la estabilidad del sistema, sin importar el esquema de supervisión que se adopte. Así, no se observa un argumento fuerte para sostener que, en este caso puntual y por definición, ambos objetivos regulatorios deban separarse orgánicamente. Por tanto, la decisión de reunir o separar la persecución de ambos objetivos obedece a razones pragmáticas y no conceptuales. El análisis a realizar consiste, entonces, en una revisión pormenorizada y precisa de los costos y beneficios asociados a cada decisión, teniendo a la vista las características específicas de un mercado financiero concreto.

Al mismo tiempo, existen formas menos disruptivas para solucionar las eventuales dificultades que pudieren surgir. Por ejemplo, puede

${ }^{200}$ H. Davies y D. Green, Global Financial Regulation: The Essential Guide (Cambridge: Polity Press, 2008), 192. 
establecerse un mandato en virtud del cual el organismo correspondiente deba procurar evitar especialmente los sesgos que pudieren derivarse de privilegiar - de forma consistente y permanente - un mandato sobre otro. Para ello, resultaría recomendable que el regulador mantenga una especial preocupación por distribuir adecuadamente su personal y recursos al cumplimiento de ambas tareas. Las mejoras de accountability que traen aparejadas los modelos integrados, y que permitirán responsabilizar al supervisor en caso de que se detecten fallas relevantes en el mercado financiero, también serán de utilidad, en tanto correctivo natural, para evitar una excesiva preocupación por uno de los objetivos regulatorios en desmedro del otro.

Dentro del segundo tipo de razones, que se relacionan con la estructura de nuestro mercado de capitales, es necesario constatar que Chile tiene un tamaño y una importancia modesta en el concierto de la economía mundial, a la vez que un mercado financiero pequeño, con relevantes niveles de concentración y una elevada presencia de conglomerados financieros. ${ }^{201}$ Dichas características lo hacen asimilable a una serie de países pequeños que han optado por instaurar modelos integrados o semi integrados de supervisión. ${ }^{202}$ En opinión de Taylor, principal defensor de los esquemas de twin peaks, "en países relativamente pequeños con sistemas financieros dominados por un número pequeño de conglomerados financieros, combinar todas las funciones regulatorias al interior de un único organismo parece ofrecer numerosas ganancias de eficiencia (...). Sigue existiendo un caso a favor de un organismo único en países comparativamente pequeños, donde las economías de escala que pueden alcanzarse son significativas". ${ }^{203-204}$

Los argumentos que Taylor ha denominado de "small country rationale" 205 se basan en la experiencia de países como Dinamarca,

201 Para una visión sobre la relevancia de los conglomerados financieros en Chile, ver Fondo Monetario Internacional, "Chile - Conglomerate Supervision", 2015, http://hacienda.cl./consejo-de-estabilidad-financiera/informes.html/.

202 Véase el caso de los países nórdicos en Taylor y Fleming, "Integrated Financial Supervision", o en Brown, "Consolidated Financial Regulation".

203 Taylor, "The Road", 89.

${ }^{204}$ En cualquier caso, alcanzar las economías que los modelos integrados prometen sigue siendo un desafío relevante y no se generan automáticamente. Taylor, "The Road", 89 y ss.

205 Véase Taylor y Fleming, "Integrated Financial Supervision”, 18-20. 
Noruega, Suecia y Finlandia, entre otros, que iniciaron procesos de migración hacia sistemas integrados a partir de mediados de los años 80 y que han optado por mantenerlos hasta nuestros días, soportando razonablemente bien los eventos críticos de la crisis asiática (1997) y sub-prime (2008).

En dichos países, la creación de agencias integradas de supervisión ha traído aparejada una serie de beneficios: (i) mejoras en la calidad regulatoria asociadas a la creación de organismos colegiados que gozan de mayor autonomía, independencia y calidad de la deliberación; (ii) mayores exigencias de accountability; (iii) eliminación del arbitraje regulatorio; (iv) mayores posibilidades de retención de capital humano calificado; (v) adecuado análisis de conglomerados financieros y evaluación de riesgos consolidados, y (vi) mayores niveles de consistencia regulatoria. ${ }^{206}$ A ello deben añadirse las economías de escala y de ámbito alcanzadas en muchas de las labores principales y anexas al giro de la supervisión financiera.

Los beneficios que han traído los esquemas integrados o semi integrados en dichas economías pequeñas muestran una especial simetría con los objetivos perseguidos en nuestro país. De hecho, la mayoría de ellos fueron sindicados como los principales argumentos para la reforma regulatoria que se propone en el Informe de Productividad ${ }^{207}$ que acompañó la presentación del proyecto de ley que Moderniza la Legislación Bancaria. ${ }^{208}$ En el referido informe, el ejecutivo sostuvo que el actual modelo de silos "desaprovecha economías tanto de ámbito como de escala, destacando la dificultad para compartir información y la limitación a la capacidad para sostener una visión integral sobre los conglomerados financieros y una perspectiva sistémica sobre el mercado en general". ${ }^{209}$ Del mismo modo, en opinión del ejecutivo, "esta

${ }^{206}$ Ibídem, 19.

${ }^{207}$ Hacia fines de 2016, se dictó un instructivo presidencial que obligaba a que los proyectos de ley que cumplieran determinados requisitos debían acompañar un informe en que se analizaran las alternativas estudiadas, la justificación de la elección de la solución propuesta, una estimación de sus costos y beneficios, así como de su impacto probable en la economía.

208 "Informe de productividad. Proyecto de Ley que Moderniza la Legislación Bancaria, adecuando normativa que indica". Mensaje n. ${ }^{\circ}$ 63-365. Ministerio de Hacienda, 13 de junio de 2017.

${ }^{209}$ Ibídem, 5. 
segmentación regulatoria promueve el surgimiento de distintos estándares regulatorios para actividades similares, lo que incentiva el arbitraje regulatorio al interior del sistema financiero local, el desarrollo de la denominada "banca en la sombra" e incuba nuevos focos de riesgos para el sistema financiero". 210

El mismo informe alude a la importancia de fortalecer y dotar de independencia al regulador para poder confiar en el correcto ejercicio de un mayor nivel de discrecionalidad, de introducir mecanismos de coordinación regulatoria y de disponibilidad de información, de propender hacia la convergencia de estándares y a la mitigación del arbitraje regulatorio; de limitar los riesgos de captura regulatoria, y de alcanzar eficiencias de gestión, economías de escala y de ámbito. ${ }^{211}$

A su vez, en economías pequeñas la mantención de dos agencias puede ser injustificada y costosa, tanto en términos de recursos presupuestarios como para atraer capital humano sofisticado. Por ello, los esquemas regulatorios de twin peaks tienen un caso más débil en aquellos países en que se dan los presupuestos de small country rationale. Todo lo anterior podría permitir justificar la preferencia por un modelo integrado en una economía pequeña como la chilena, que hace su realidad más comparable a la de los países nórdicos que a la de los grandes centros financieros a nivel mundial.

En tercer lugar, revisaremos algunas circunstancias que marcaron la última fase de discusión del proyecto de ley que crea la CMF. Se sostiene con relativa frecuencia que los cambios de esquemas de supervisión históricamente se han originado en situaciones de crisis y en respuesta a eventuales errores o fallas detectados en la actuación de los organismos encargados de la supervisión. ${ }^{212}$ A su vez, el sentido de las migraciones suele encontrarse directamente relacionado con - o derechamente determinado por- el tipo de fallas detectadas en el sistema y contra las cuales se reacciona.

El ejemplo del Reino Unido puede ser especialmente ilustrativo. Hasta fines de los años 90, el Reino Unido contaba con un sistema

${ }^{210}$ Ibídem.

211 Ibídem.

212 De hecho, se suele citar a Australia como el caso en que se realizó una migración de esquema de supervisión sin estar sometido a la presión de un evento crítico. 
disgregado de supervisión en que existían al menos nueve organismos involucrados. Luego de la crisis asiática se detectaron numerosas fallas relacionadas con problemas de coordinación, disparidad de estándares exigibles, arbitrajes regulatorios, actividades sin supervisión y una serie de problemas directamente relacionados con una estructura de supervisión fragmentada. Con dicho diagnóstico, la solución consistió en realizar una gran consolidación del esquema de supervisión, fusionando la totalidad de los organismos competentes en una única entidad: Financial Services Authority (FSA), ${ }^{213}$ absorbiendo incluso competencias del Banco de Inglaterra, su banco central. ${ }^{214}$

Casi una década más tarde, y en el contexto de la crisis subprime, se produjo la caída del Northern Rock Bank, con todos los problemas que ello trajo aparejados. En el período de evaluación de las causas de dicha caída y de la eventual responsabilidad de la FSA, se llegó a la conclusión de que dicho organismo había tenido serios problemas para: (i) velar adecuadamente por sus objetivos prudenciales y conductuales, privilegiando los segundos y relegando los primeros, ${ }^{215} \mathrm{y}$ (ii) hacer funcionar un organismo compuesto por la fusión de nueve entidades con culturas organizacionales difíciles de conciliar. Habiéndose detectado dichos problemas, la solución natural fue migrar hacia un modelo de cumbres gemelas que le permitiere diferenciar claramente preocupaciones prudenciales y conductuales, así como distribuir de modo operativo los departamentos que respondían a culturas organizacionales semejantes. ${ }^{216}$ En razón de lo anterior, se pasó a un modelo de twin peaks, en el que existe un regulador prudencial (Prudential Regulation Authority) y otro de vocación conductual (Financial Conduct Authority). ${ }^{217}$

Ahora bien, los problemas de respuesta que mostraron los esquemas de supervisión en el Reino Unido en contextos de crisis no garantizan que el sistema al que se migró en cada caso hubiese respondido

${ }^{213}$ Brown, "Consolidated Financial Regulation", 73.

214 Taylor, "The Road", 63-64.

215 Ibídem, 81-82.

${ }^{216}$ Brown, "Consolidated Financial Regulation", 74.

217 Para una explicación detallada del caso del Banco Northern Rock, véase, Shin, "Reflections on Modern Bank Runs: A Case Study of Northern Rock", Journal of Economic Perspectives 23, n. ${ }^{\circ} 1$ (2009). 
mejor en iguales circunstancias. La ausencia de un contrafactual comparable no permite sacar conclusiones relevantes al respecto. ${ }^{218}$

Sin embargo, la experiencia del Reino Unido permite ilustrar que en procesos de revisión de esquemas institucionales de supervisión financiera resulta natural migrar hacia aquellos modelos que mejor responden ante el conjunto de problemas que gatillaron la necesidad de revisión. Si el diagnóstico es que existe demasiada fragmentación regulatoria, resultará natural migrar hacia modelos integrados; si el problema detectado es la dificultad de velar adecuadamente por objetivos prudenciales y conductuales, probablemente la respuesta será moverse hacia un esquema de twin peaks. ${ }^{219}$

En la discusión nacional es posible observar el mismo patrón. Los escándalos financieros suscitados en 2016 permitieron constatar la existencia de graves problemas de coordinación entre los supervisores financieros, débil ejercicio de su potestad normativa, carencia de información disponible y de mecanismos para compartirla, interpretaciones discutibles acerca de sus perímetros regulatorios, riesgos de arbitrajes y de surgimiento de actividades no fiscalizadas, problemas de accountability, dilución de responsabilidades y falta de independencia. ${ }^{220}$ Dado que tales deficiencias fueron de alta connotación pública y adquirieron una gran relevancia política, no resulta extraño que la respuesta legislativa haya sido migrar hacia un modelo de supervisión más integrado. Ello, pues, como vimos, dicho esquema es el que mejor se enfrenta a la constelación de problemas específicos que formaron parte del diagnóstico de falencias de nuestro sistema al momento de su revisión. ${ }^{221}$

${ }^{218}$ De hecho, el caso holandés — país en que los efectos de la crisis subprime fueron graves - nos permite ilustrar que el modelo de twin peaks, al que el Reino Unido terminó migrando, se mostró igualmente vulnerable al enfrentar un escenario crítico. Véase Schmulow citado en Ministerio de Hacienda, "Informe de productividad", 18.

${ }^{219}$ Son observables experiencias similares a las del Reino Unido en otros países. Véase Brown, "Consolidated Financial Regulation".

${ }^{220}$ Cámara de Diputados, "Informe" 75 y ss.

${ }^{221}$ Un fenómeno similar es observable en la actual discusión norteamericana. Dado que hoy dicho sistema cuenta con 116 organismos con competencias en la supervisión del mercado, la mayoría de las propuestas de reforma que han sido presentadas ante el Congreso Nacional durante los últimos cien años recomiendan algún grado relevante de consolidación regulatoria. Véase, Brown, "Prior Proposals" y Brown, "The New Laws", 6. 


\section{CONCLUSIONES}

Los problemas de diseño institucional asociados a los esquemas de supervisión financiera son complejos y la revisión de experiencia comparada demuestra que no existe una solución única a la que los países desarrollados se encuentren convergiendo. Ninguna nación ha inventado un sistema de supervisión perfecto y todas las alternativas disponibles se encuentran expuestas a relevantes críticas. Además, el esquema que se adopte, cualquiera que éste sea, no garantizará en caso alguno una correcta supervisión del mercado financiero. Un correcto diseño institucional es apenas el punto de partida.

En Chile, la Ley 21.000 y el Proyecto de Ley que Moderniza la Legislación Bancaria suponen un avance relevante hacia un modelo semi integrado de supervisión financiera. De aprobarse dicha iniciativa, la CMF asumirá objetivos conductuales y prudenciales que anteriormente eran de responsabilidad de la SVS y SBIF. Ahora bien, no serán alteradas las competencias de la Superintendencia de Pensiones, del Banco Central de Chile - organismo que tiene relevantes preocupaciones macroprudenciales - ni del Servicio Nacional del Consumidor en materia financiera. Todo lo anterior, distingue la solución chilena de un esquema integrado en estado puro. Al mismo tiempo, ello debiese reducir o morigerar los riesgos de sesgo del regulador con que se critica a los esquemas integrados propiamente tales.

Pese a que la discusión académica y de los actores incumbentes ha posicionado el esquema de twin peaks como la mejor alternativa para ser aplicada en Chile, en nuestra opinión la solución adoptada de supervisión semi integrada parece natural y se encuentra razonablemente fundada, debido a que los objetivos prudenciales y conductuales no son conceptualmente irreconciliables y se encuentran alineados en el largo plazo; las características especiales del mercado financiero chileno, su tamaño, complejidad y profundidad, le permitirán capturar eficiencias relevantes, dado su small country rationale; y constituye una respuesta efectiva ante el diagnóstico concreto sobre los principales problemas de nuestro actual esquema de supervisión. Esperamos que los argumentos esgrimidos en el presente artículo resulten útiles para tensionar la visión hegemónica favorable al esquema twin peaks y, al mismo tiempo, justificar la decisión adoptada. 
Ahora bien, como el cambio de diseño institucional es sólo el punto de partida de una reestructuración completa de nuestro actual esquema de supervisión, la CMF deberá asumir, en los próximos años, una serie de desafíos importantes. Primero, tendrá que definir la forma de organización interna que adoptará. Probablemente, deberá ensayar distintos esquemas hasta encontrar una fórmula afinada. La flexibilidad interna, como dijimos, es una de las ventajas de los esquemas integrados.

Por otra parte, la Comisión debiese iniciar un proceso de revisión regulatoria para generar mayores niveles de coherencia entre los distintos sectores regulados. Del mismo modo, debiese eliminar regulación innecesaria y simplificar aquella que genere excesiva incertidumbre. Todo ello, contribuirá a mejorar los niveles de innovación e intensificar la competencia en el mercado.

Finalmente, la Comisión debiese abrir el camino hacia una administración con un fuerte mandato prospectivo y con un ámbito relevante de discrecionalidad en las decisiones regulatorias que adopte. Un gobierno corporativo fuerte, colegiado e independiente, así como el nuevo estándar de fundamentación de decisiones que incorpora la Ley 21.000 debiesen generar mayores niveles de confianza en el regulador y, por tanto, tender a flexibilizar las exigencias de una concepción estricta $-\mathrm{y}$ a veces inconducente - del principio de legalidad de la actuación de los órganos administrativos.

En los mercados financieros mundiales se ha observado una tendencia hacia regular por medio de más principios y menos reglas. ${ }^{222}$ Esta forma de aproximación a los problemas regulatorios exige mayores niveles de confianza en la actuación del regulador, y el diseño de la CMF ofrece, en nuestra opinión, suficientes garantías como para dar ese paso. Todo ello permitirá que el nuevo organismo encargado de la supervisión financiera se encuentre en una posición privilegiada para equilibrar adecuadamente los mandatos de autonomía, por una parte, y de responsividad, por la otra.

Para terminar, resulta fundamental hacer notar que, en los próximos años, deberemos enfrentar interesantes desafíos legislativos tendientes a: (i) proveer de un esquema moderno de resolución de entidades financieras en problemas, y (ii) establecer un mecanismo adaptable

222 Para un análisis temprano del fenómeno, véase L. Kaplow, "Rules Versus Standards: An Economic Analysis", Duke Law Journal 42 (1992). 
de determinación del perímetro regulatorio de la CMF. Abordar tales desafíos pendientes será imprescindible para consolidar un esquema regulatorio acorde a los desafíos actuales de supervisión financiera.

\section{BIBLIOGRAFÍA}

Acharya, Viral. "A Theory of Systemic Risk and Design of Prudential Bank Regulation". Journal of Financial Stability 5, n. ${ }^{\circ} 3$ (2009): 224-255.

Admati, Anat \& Martin Hellwig. The Bankers' New Clothes: What's Wrong with Banking and What to Do about it. Princeton: Princeton University Press, 2013.

Alessandri, Arturo. La autocontratación o el acto jurídico consigo mismo. Santiago: Imp. Cervantes, 1931.

Alexander, Kern. "Bank Resolution Regimes: Balancing Prudential Regulation and Shareholder Rights". Journal of Corporate Law Studies 9, n. ${ }^{\circ}$ (2009): 61-93.

Armour, John. "Bank Resolution Regimes: Designing the Right Model?". Artículo inédito (2010). http://bfsla.org/wp-content/uploads/papers/2010/Bank\%20 Resolution\%20Regimes\%20-\%20Designing\%20the\%20Right\%20Model\%20 -\%20Armour.pdf/.

Armour, John, Henry Hansmann \& Reinier Kraakman. "Agency Problems, Legal Strategies, and Enforcement”. Oxford Legal Studies Research Paper 21 (2009).

Arrow, Kenneth J. Essays in the Theory of Risk-Bearing. Amsterdam-London: North-Holland, 1970.

Atiyah, Patrick. "Form and Substance in Contract Law". En Essays on Contract, de Patrick Atiyah. USA: Oxford University Press, 1990.

Atria, Fernando. La forma del derecho. Madrid: Marcial Pons, 2016.

BaFin. Annual Report, Bundesanstalt für Finanzdienstleistungsaufsicht. 2002. https://www.bafin.de/SharedDocs/Downloads/EN/Jahresbericht/dl_jb_2002_a_ en.pdf?_blob=publicationFile\&v $=2 /$.

Baldwin, Robert, Martin Cave \& Martin Lodge. Understanding Regulation: Theory, Strategy, and Practice. Nueva York: Oxford University Press, 2012.

Borio, Claudio \& Renato Filosa. "The Changing Borders of Banking: Trends and Implications". BIS Working Papers 23 (1994). http://dx.doi.org/10.2139/ ssrn.868431/.

Briault, Clive. "The Rationale for a Single National Financial Services Regulator". Financial Services Authority Occasional Paper 2 (1999). http://dx.doi. org/10.2139/ssrn.428086/.

- "Revisiting the Rationale for a Single National Financial Services Regulator". UK, FSA Occasional Paper Series 16 (2002). http://dx.doi. org/10.2139/ssrn.427583/. 
Brown, Elizabeth. "E Pluribus Unum-Out of Many, One: Why the United States Needs a Single Financial Service Agency". University of Miami Business Law Review 14 (2005).

-. "A Comparison of the Handling of the Financial Crisis in the United States, the United Kingdom, and Australia”. Villanova Law Review 55, n. ${ }^{\circ} 3$ (2010): 509-576.

_. "The New Laws and Regulations for Financial Conglomerates: Will They Better Manage the Risks than the Previous Ones?". American University Law Review 60-5, n² (2011): 1339-1415.

- "Consolidated Financial Regulation: Six National Case Studies and the Experience of the European Union". The Volcker Alliance. Working for Effective Government, 2015. https://ssrn.com/abstract=2732083/.

_. "Prior Proposals to Consolidate Federal Financial Regulators". The Volcker Alliance. Working for Effective Government, 2015. https://ssrn.com/ abstract $=2732082 /$.

Brown, Elizabeth \& Edward Buckley. "A Preliminary Look at State Structures for Regulating Financial Services". U. of St. Thomas Legal Studies Research Paper 07-42 (2014). http://dx.doi.org/10.2139/ssrn.1008961/.

Brunnermeier, Markus, Andrew Crocket, Avinash Persaud, Hyun Song Shin \& Charles Goodhart. "The Fundamental Principles of Financial Regulation". Geneva Reports on the World Economy 11, International Center for Monetary and Banking Studies (ICMB) (2009).

Cámara de Diputados. Informe de la comisión investigadora de la actuación de los organismos públicos competentes en relación al eventual fraude de empresas de inversión. Congreso de Chile, 2016.

Chant, John. "Keeping the Genie in the Bottle: Grading the Regulation of Canadian Financial Institutions”. SPP Research Paper 7-8 (2014). https://ssrn.com/ abstract $=2408744$.

Claessens, Stijn \& Laura Kodres. "The Regulatory Responses to the Global Financial Crisis: Some Uncomfortable Questions”. IMF Working Paper 14/46 (2014).

Cooper, Jeremy. "The Integration of Financial Regulatory Authorities - The Australian Experience". Assessing the Present, Conceiving the Future. Discurso ante la Comissão de Valores Mobiliários, Rio de Janeiro (2006).

Cordero, Luis, Fernando Coloma, Matías Larraín \& Guillermo Tagle. Informe final. Grupo de trabajo para el fortalecimiento institucional del mercado de capitales. Santiago, 2015.

Davies, Geoff \& Marc Dobler. "Bank Resolution and Safeguarding the Creditors Left Behind”. Bank of England Quarterly Bulletin Q3 (2011). https://ssrn. com/abstract $=1933776 /$.

Davies, Howard \& David Green. Global Financial Regulation: The Essential Guide. Cambridge: Polity Press, 2008.

De Gregorio, José. "Chile frente a la recesión mundial de 2009”. Estudios Públicos 113 (2009): 5-26. 
De Luna Martínez, José \& Thomas Rose. "International Survey of Integrated Financial Sector Supervision". Policy Research Working Paper 3096, World Bank (2003).

Desormeaux, Jorge, Arturo Cifuentes, Luis Cordero, Pablo Correa, Ronald Fischer, Alejandro Ferreiro \& Arturo Yrarrázaval. Informe final. Comisión de reforma a la regulación y supervisión financiera. Santiago, 2011.

Dewatripont, Mathias \& Xavier Freixas. "Bank Resolution: A Framework for the Assessment of Regulatory Intervention”. Oxford Review of Economic Policy 27, n. ${ }^{\circ} 3$ (2011): 411-436.

Dewatripont, Mathias \& Jean Tirole. The Prudential Regulation of Banks. Cambridge, Mass: MIT Press, 1994.

Downe, Bill. "The Canadian Banking Model and Lessons Learned from the Global Financial Crisis". Policy Options, junio (2010).

Drake, Paul. "La Misión Kemmerer a Chile: consejeros norteamericanos, estabilización y endeudamiento, 1925-1932”. Cuadernos de Historia 4 (1981): 31-59.

Dworkin, Ronald. "Is Wealth a Value?". The Journal of Legal Studies 9, n. ${ }^{\circ} 2$ (1980): 191-226.

Epstein, Richard. Reglas simples para un mundo complejo. Lima: Pontificia Universidad Católica del Perú, 2005.

Financial Stability Board. Key Attributes of Effective Resolution Regimes for Financial Institutions, 2014.

Fischer, Stanley. "Preparing for Future Crises". Conferencia Anual de Jackson Hole, 2009.

Fondo Monetario Internacional. "Chile - Conglomerate Supervision”. 2015. http:// hacienda.cl./consejo-de-estabilidad-financiera/informes.html/.

Goodhart, Charles. "Some Regulatory Concerns; and An Incentive Structure for Financial Regulation". Swiss Journal of Economics and Statistics (SJES) 132, n. ${ }^{\circ} 4$ (1996): 613-636.

. "The Organisational Structure of Banking Supervision". Economic Notes 31, n. ${ }^{\circ}$ (2002): 1-32.

Goodhart, Charles, Phillip Hartmann, David Llewellyn, Liliana Rojas-Suárez \& Steven Weisbrod. Financial Regulation: Why, How and Where Now? Londres y Nueva York: Routledge, 1998.

Group of Thirty. The Structure of Financial Supervision: Approaches and Challenges in a Global Marketplace. Washington, 2008.

Hellmann, Thomas, Kevin Murdock \& Joseph Stiglitz. "Liberalization, Moral Hazard in Banking, and Prudential Regulation: Are Capital Requirements Enough?". The American Economic Review 90, n. ${ }^{\circ} 1$ (2000): 147-165.

Her Majesty's Treasury. Financial Services and Markets Bill: A Consultation. 1998.

Kaplow, Louis. "Rules Versus Standards: An Economic Analysis". Duke Law Journal 42 (1992): 557. 
Kern, A. "Bank Resolution Regimes: Balancing Prudential Regulation and Shareholder Rights". Journal of Corporate Law Studies 9, n. ${ }^{\circ} 1$ (2009).

King, Mervyn. "Speech at the Lord Mayor's Banquet for Bankers and Merchants of the City of London at the Mansion House". 2010.

Kremers, Jeroen \& Dirk Schoenmaker. "Twin Peaks: Experiences in the Netherlands”. LSE Financial Markets Group Paper Series, Special Paper 196 (2010).

Lambeth, George \& Diego Morales. "La Comisión para el Mercado Financiero y el perímetro regulatorio del regulador: algunas notas sobre sus implicancias". Anuario de Derecho Público 1, Universidad Diego Portales (2017): 241-266.

Larraín, Matías. "Notas al último intento de reforma del sistema de supervisión financiera". Anuario de Derecho Público 1, Universidad Diego Portales (2012): 392-414.

Larraín, Matías \& Guillermo Larraín. "Hacia una reforma de la institucionalidad financiera en Chile". Documento de Trabajo 12, Facultad de Gobierno, Universidad del Desarrollo (2010).

Lira, Pedro. El Código Civil chileno y su época. Santiago: Editorial Jurídica de Chile, 1956.

Llewellyn, David. "Institutional Structure of Financial Regulation and Supervision: The Basic Issues. Aligning Supervisory Structures with Country Needs". Conferencia en World Bank Seminar Aligning Supervisory Structures with Country Needs, Washington DC, 6th and 7th June, 2006.

Macey, Jonathan. "Organizational Design and Political Control of Administrative Agencies". Journal of Law, Economics \& Organization 8, n. 1 (1992).

Ministerio de Hacienda. "Informe de productividad. Proyecto de Ley que Moderniza la Legislación Bancaria, adecuando normativa que indica”. Mensaje 63365, 13 de junio de 2017.

Misky, Hyman. Stabilizing an Unstable Economy. Nueva York: MacGraw Hill, 2008.

Montt, Santiago. "Autonomía y responsividad: dos expresiones de la vocación juridificadora del derecho administrativo y sus principios fundamentales". Centro de Regulación y Competencia, Universidad de Chile. 2010.

Mori, Nobuchika. From Static Regulation to Dynamic Supervision: Speeches by Commissioner Nobuchika Mori. Tokyo: Financial Services Agency of Japan. 2017.

Mwenda, Kenneth. "Legal Aspects of Unified Financial Services Supervision in Germany". German Law Journal 4 (2003): 1009.

Nonet, Phillipe \& Phillip Selznick. Law and Society in Transition: Toward Responsive Law. New Jersey: Transaction Publishers, 1978.

OCDE. The Governance of Regulators. OECD Best Practice Principles for Regulatory Policy. París: OECD Publishing, 2014.

Office of the Comptroller of the Currency. US Department of the Treasury. National Banks and the Future. U.S. Government Printing Office, 1962. 
Pardow, Diego. “¿Control o autonomía?: El debate sobre agencias regulatorias independientes". Artículo inédito.

"La experiencia chilena disuadiendo ilícitos corporativos". Revista Derecho Público Iberoamericano 1 (2012): 55-83.

. "El Servicio Nacional del Consumidor de Chile (Sernac) y los reguladores sectoriales: buscando mecanismos para una mejor coordinación”. Revista Economía y Política 2, n. ${ }^{\circ}$ (2015): 107-136.

Posner, Rirchard. "Utilitarianism, Economics, and Legal Theory". The Journal of Legal Studies 8, n. ${ }^{\circ} 1$ (1979): 103-140.

Rawls, John. "Dos conceptos de reglas". En Teorías sobre la ética, de John Rawls, 210-247. México D.F.: Fondo de Cultura Económica, 1955.

Schooner, Heidi \& Michael Taylor. "United Kingdom and United States Responses to the Regulatory Challenges of Modern Financial Markets". Texas International Law Journal 38, n. ${ }^{\circ} 2$ (2003).

Shin, Hyun Song. "Reflections on Modern Bank Runs: A Case Study of Northern Rock". Journal of Economic Perspectives 23, n. ${ }^{1}$ (2009): 101-119.

Tarullo, Daniel. "Rethinking the Aims of Prudential Regulation”. En Bank Structure Conference, Federal Reserve Bank of Chicago, 2014.

Taylor, Michael. “'Twin Peaks': A Regulatory Structure for the New Century”. Centre for the Study of Financial Innovation, 1995.

_. "Peak Practice: How to Reform the UK's Regulatory System". Centre for the Study of Financial Innovation, 1996.

. "“Twin Peaks' Revisited... A second chance for regulatory reform”. Centre for the Study of Financial Innovation, 2009.

_. "The Road from 'Twin Peaks' and the Way Back". Connecticut Insurance Law Journal 16, n. ${ }^{\circ} 1$ (2009): 61-96.

Taylor, Michael \& Richard Abrams. "Issues in the Unification of Financial Sector Supervision”. Working Paper 00/213, International Monetary Fund (2000).

Taylor, Michael \& Alex Fleming. "Integrated Financial Supervision: Lessons of Northern European Experience". Policy Research Working Paper Series 2223, World Bank (1999).

The Economist. "A Survey of Global Equity Markets: Regulators' Arbitrage". 3 de mayo, 2001.

Thompson, Graeme. "Regulatory Policy Issues in Australia". Reserve Bank of Australia, 1996.

Tripartite Group of Bank, Securities and Insurance Regulators. The Supervision of Financial Conglomerates, 1995.

Wallis, Stan. Financial System Inquiry Final Report (Wallis Inquiry). Australia: Australian Goverment, 1997. EP 